\title{
Aspects of Numerical Modelling of Flash-Boiling Fuel Sprays
}

\author{
Christopher Price, Arash Hamzehloo and Pavlos Aleiferis
}

University College London, UK

\section{David Richardson}

Jaguar Land Rover, UK

Copyright $(2015$ SAE International

\begin{abstract}
Flash-boiling of sprays may occur when a superheated liquid is discharged into an ambient environment with lower pressure than its saturation pressure. Such conditions normally exist in direct-injection spark-ignition engines operating at low incylinder pressures and/or high fuel temperatures. The addition of novel high volatile additives/fuels may also promote flashboiling. Fuel flashing plays a significant role in mixture formation by promoting faster breakup and higher fuel evaporation rates compared to non-flashing conditions. Therefore, fundamental understanding of the characteristics of flashing sprays is necessary for the development of more efficient mixture formation. The present computational work focuses on modelling flash-boiling of $n$-Pentane and isoOctane sprays using a Lagrangian particle tracking technique. First an evaporation model for superheated droplets is implemented within the computational framework of STAR$\mathrm{CD}$, along with a full set of temperature dependent fuel properties. Then the computational tool is used to model the injection of flashing sprays through a six-hole asymmetric injector. The computational results are validated against optical experimental data obtained previously with the same injector by high-speed imaging techniques. The effects of ambient pressure ( 0.5 and 1.0 bar) and fuel temperature (20$180^{\circ} \mathrm{C}$ ) on the non-flashing and flashing characteristics are examined. Effects of initial droplet size and break-up submodels are also investigated. The computational methodology is able to reproduce important physical characteristics of flashboiling sprays like the onset and extent of spray collapse. Based on the current observations, further improvements to the mathematical methodology used for the flash-boiling model are proposed.
\end{abstract}

\section{INTRODUCTION}

\section{Flash-Boiling Atomization}

Flash-boiling is the rapid phase transition from liquid to vapor when a liquid spray is discharged into an ambient environment with lower pressure than the saturation pressure of the fuel. Under this condition fuel droplets are superheated and enter a

Page 1 of 23 metastable state, where the latent heat is consumed by bubble nucleation within the liquid. Bubbles created at nucleation sites can continue to grow or collapse depending on the local fuel conditions surrounding each bubble and the size of the vapor bubble itself. Many forms of bubble nucleation and flashing can occur including: heterogeneous nucleation where bubbles form on surfaces and discontinuities, homogeneous nucleation where bubbles form everywhere inside the liquid, combination of internal and external flashing, etc. The type of flashing and its characteristics depend on various parameters including: nozzle geometry, fuel properties and environmental conditions. Internal nucleation and bubble growth/bursting in fuel injectors can form a gaseous phase within the nozzle volume which may then create an under-expanded jet of fuel vapor at the nozzle exit (with embedded liquid droplets). This occurs due to the high injection pressures typically used with gasoline direct injection, currently up to 200 bar. On the other hand, external flashing occurs when the majority of bubble growth and bursting occurs just past the nozzle exit.

The conditions in which a flash-boiling spray may form, can occur in direct-injection gasoline engines when operating at low-load warm conditions with early intake stroke injection strategies to promote mixture homogeneity (i.e. injection of high-temperature fuel into low in-cylinder pressure). Particular engine operating strategies such as early intake valve closure (which can lead to a partial in-cylinder vacuum) can promote flashing conditions [1]. Highly boosted downsized engines can transfer a higher amount of heat into the fuel via heat transfer through the injector, increasing the latent heat, and in turn producing further flashing mechanisms [2]. It is worth mentioning that under the aforementioned conditions flashboiling may occur under conventional gasoline fuelling due to the existence of high volatile components such as $n$-Pentane.

A strong initiative to use cleaner and more sustainable alternative fuels is an essential path for future internal combustion (IC) engine development due to the ever increasing cost of conventional hydrocarbon fuels, the global obligation to reduce carbon-based emissions and the current fuel supply uncertainty [3]. The majority of novel fuels and additives have high volatilities, which can influence the spray formation in a similar way to increasing fuel temperature or reducing ambient pressure. For example, the addition of 
ethanol to gasoline can have a significant influence on the spray formation due to an increased evaporation rate or flashing phenomena, even at low blending ratios [4]-[9]. With the inevitable increase in global consumption of new fuel blends, it is essential to understand the effect of flash-boiling on spray formation with a range of components. A typical pump-grade gasoline contains very many individual fuel components, each comprising of different thermophysical properties. The variation in volatility, as well as properties such as surface tension, specific heat and viscosity of each component, can influence the formation of the spray as single components can flash-boil individually and affect the behaviour of droplets. Previous experimental studies [9] whereby both single and multi-component fuels were injected into a quiescent chamber at superheated conditions, have shown that high volatility single components like $n$-pentane can be used to represent the behavior of gasoline since it is these components within gasoline's multicomponent blend that drive the spray's collapsing mechanism.

Flash-boiling of liquid fuel sprays can play a beneficial role in mixture formation, as increased evaporation rates and enhanced atomization can produce a more homogeneous fuel mixture, which may result in more efficient and cleaner combustion. The droplet sauter mean diameter (SMD) of a flashing spray is significantly smaller than a non-flashing spray at the same injection pressure ratio [10], [11]. This generally causes a reduction in spray penetration due to smaller droplets having less inertia. However, depending on the number of injection holes and proximity of plumes from individual holes, effects may involve severe plume merging and increased axial momentum, hence longer axial overall spray penetration. The shortened or elongated penetration may reduce or exacerbate droplet-wall impingement which in turn can affect the formation of tailpipe emissions such as particulates and unburnt hydrocarbons.

The majority of work carried out on flash-boiling sprays over the last four decades has been experimental, as the underlying mechanisms are extremely difficult to understand on a fundamental level and model appropriately. Sher and Elata [12] were among the first to develop empirical models to predict bubble growth rates and droplet sizes caused by flashboiling. A relationship between average droplet size, nozzle pressure ratio and fuel properties was developed and validated against flashing sprays formed using a "pressure-can" apparatus. Kitamura et al. [13] went on to quantitatively predict the critical superheat for the onset of flashing in superheated liquid jets. It was found that the critical superheat for a complete flashing spray was well above the bubble-point and depended on several parameters including injection velocity and nozzle diameter. Numerous other parameters have since been characterized by Sher et al. [14], specifically fuel surface tension, fuel viscosity, nozzle surface roughness, injection pressure and nozzle geometry.

Another important aspect in numerical modelling of flashboiling is the effect of the superheated condition on the rate of heat and mass transfer. Adachi et al. [15] measured and theoretically derived relationships regarding the evaporation of superheated sprays. Using an infrared extinction/scattering technique, fuel vapor concentrations were characterized, and used to successfully validate the theoretical heat and mass transfer models developed. It was concluded that a more homogenous mixture was produced with a significant increase in the evaporation rate when flash-boiling was observed.

One of the first attempts to numerically model the atomization and vaporization of a flash-boiling spray was conducted using the classical nucleation theory [16]. The numerical model included bubble nucleation, bubble growth, vapor formation and droplet formation. Bubble size and droplet sizes were estimated, and coincided with experimental data reasonably well. However, a computational fluid dynamics (CFD) approach was not undertaken and spatial/temporal spray structures were not modelled.

$\mathrm{Ra}$ and Reitz [17] focused on droplet evaporation of a single droplet, at temperatures ranging from 'normal' to 'flashboiling' conditions. Here an unsteady internal heat flux and surface temperature model were proposed. The modified evaporation model developed was used with both multicomponent gasoline and iso-octane fuel sprays, whereby the KIVA-3V code was used to simulate a hollow-cone injector at relatively low in-cylinder pressures. It was found that multicomponent fuel models can produce a large variation in vapor distribution when compared to single component fuel models for a hollow cone spray. The devised surface temperature calculation and internal heat flux model offered an improvement in predicted evaporation rates.

\section{Present Contribution}

The fundamental mechanism of flash-boiling fuel sprays is still under debate due to the difficulty associated with experimentally quantifying areas of dense spray close to the nozzle exit and flow properties inside working injectors. Limitations also lie with current empirical models as they have been developed for a specific range of liquids and operating conditions [18]. Currently there is very limited computational work available in the literature that has discussed methods for successfully modelling multi-hole flashing sprays under engine-like conditions, as well as capturing the mechanism of spray collapse that can lead to quite complex spray structures and affect the in-cylinder mixture formation. The current study attempts to formulate and validate a computational framework for flash-boiling fuel spray modelling based on a two-phase Lagrangian particle tracking (LPT) methodology. The main objectives of the present work can be summarized as follows:

- To implement in a CFD code an evaporation model which incorporates additional evaporation caused by superheated droplets and study its effects.

- To conduct a preliminary validation of the numerical framework against optical experimental data obtained

Page 2 of 23 
previously in-house with a specific multi-hole injector using fuels of different volatilities.

- To use the developed flash-boiling spray model to investigate the influence of auxiliary sub-models including droplet break-up and droplet collision models on spray characteristics.

- To examine the effect of various spray parameters, like the initial droplet diameter and plume cone angle, on the formation of flash-boiling sprays and the associated mechanism of 'spray collapse'.

\section{NUMERICAL METHODOLOGY}

\section{Modelling Approach}

A flash-boiling evaporation model was implemented into STAR-CD using its FORTRAN-based user-coding capability which is documented later in this paper. A coupled Lagrangian-Eulerian framework was used to enable numerical modelling of a dispersed multi-phase flow. A Lagrangian particle tracking technique was used whereby governing equations (i.e. the conservation of mass, momentum and energy) are solved for the individual elements of the dispersed phase (using the stochastic parcel approach where individual droplets are grouped into 'parcels' and assumed to have identical physical properties). The continuous phase which is expressed in Eulerian form is solved in the same manner; it incorporates source terms in order to allow for mass, momentum and energy transfer with the dispersed phase, hence a coupled two-phase flow framework. The PISO pressure-velocity coupling algorithm is used as originally proposed by Isaa [19], along with the second-order Monotone Advection and Reconstruction Scheme (MARS) for both momentum and turbulence of the Eulerian phase. The Lagrangian phase is modelled using first-order ordinary differential equations.

Turbulence was modelled using a Reynolds-averaged NavierStokes (RANS) approach by employing an eddy viscosity model. Specifically the $k$ - $\varepsilon / \mathrm{RNG}$ (Re-Normalization Group) model developed by Yakot et al. [20] was selected. This model has shown good accuracy for non-fuelled in-cylinder flow modelling work by one of the authors of the current work [21]. Therefore, it was chosen to maintain consistency with future modelling of fuelled in-cylinder flow and mixture formation using the developed framework. With the high velocity flow field and shear layers generated by high pressure injection, turbulent dispersion was included in the modelling approach by a random walk technique [22].

Two single-component fuels were investigated, namely isoOctane and $n$-Pentane, to represent a medium and high volatility component of gasoline, respectively. Temperature dependent polynomial relationships for the thermo-physical properties of those fuels were taken from the Yaws' database [23] and implemented via user coding as well. The fuel properties modelled include; surface tension, viscosity, latent

Page 3 of 23 heat of vaporization, density, specific heat capacity, saturation pressure and thermal conductivity. The polynomials are documented in Appendix A. Vapour densities were modelled by the ideal gas law.

\section{Flash-Boiling Evaporation Model}

Numerical modelling of superheated fuel injection requires an evaporation model which can account for heat transfer from the surrounding environment and from the superheated droplet itself. Here the flash-boiling evaporation model implemented is described. The following assumptions were made: 1) the droplet is spherical, 2) at superheated conditions the droplet surface temperature is equal to the saturation temperature of the fuel and 3) the type of flash-boiling being modelled is external flash-boiling as disputed by Reitz [24]. Also, considering the small ratio of length/diameter of the nozzle hole used in the current investigation [8], [25], [26], bubble bursting and consequent flashing occurs close-to or downstream of the nozzle exit plane.

Displayed in Figure 1 is a schematic showing the direction of heat transfer and surface evaporation for a superheated droplet. At superheated conditions, heat from the surrounding environment (referred to as subcooled evaporation from hereafter), as well as heat from the droplet center (referred to as superheat evaporation from hereafter), contribute to the droplet surface evaporation. At subcooled conditions heat transfer from the center of the droplet is assumed to be negligible.

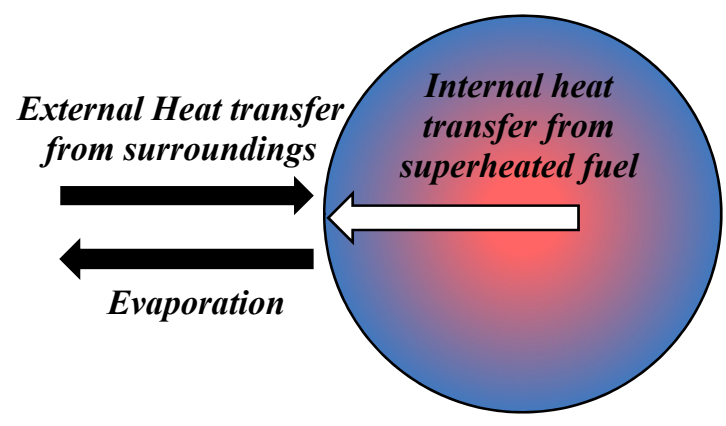

Figure 1. Schematic of heat-transfer at droplet temperatures above and below the boiling temperature of the fuel.

The subcooled droplet evaporation term, $M_{s c 1}$ can be calculated as follows [27]:

$$
\frac{d M_{s c 1}}{d t}=A P \frac{S h D_{i}}{T_{f} R_{f} D_{d}} \ln \left(\frac{P-P_{v}}{P-P_{s}}\right)
$$

where $A$ is the surface area of the droplet, $P$ the ambient pressure, $S h$ is the non-dimensional Sherwood number, $D_{i}$ the binary diffusivity coefficient, $T_{f}$ the temperature of the vapor film assumed to be the average of the droplet temperature and surrounding gas temperature, $R_{f}$ the specific gas constant of 
the vapor film, $D_{d}$ the droplet diameter and $P_{v}$ and $P_{s}$ the partial vapor pressure in the cell and saturation pressure of the fuel, respectively. Formulation of non-dimensional numbers used in the current work can be found in Appendix A.

A second formulation of an evaporation model was also implemented and compared to the model documented in Equation 1. The subcooled evaporation rate is given as [28]:

$$
\frac{d M_{s c 2}}{d t}=A P \frac{S h D_{i}}{T_{f} R_{f} D_{d}} \ln \left(\frac{1-Y}{1-Y_{s}}\right)
$$

where $Y$ is the instantaneous mass fraction of vapor in the cell and $Y_{s}$ is the fuel vapor mass fraction at the droplet surface, given as:

$$
Y_{s}=\frac{P_{s} m_{v}}{P_{s} m_{v}+\left(P-P_{s}\right) m_{a}}
$$

Here $m_{v}$ and $m_{a}$ represent the molecular weight of fuel and air, respectively. The formulation of $M_{\mathrm{sc} 1}$ is based on the mole fraction whereas $M_{\mathrm{sc} 2}$ is calculated using mass fraction as seen in Equation 2.

Then a superheated droplet evaporation term, $M_{s h}$, was implemented in the code. This term was originally suggested by Adachi et al. [29] and can be summarized as follows:

$$
\frac{d M_{s h}}{d t}=\frac{A \alpha \Delta T}{H_{V}}
$$

where $\Delta T$ is the degree of superheat, $\alpha$ is a heat transfer coefficient and $H_{V}$ is the latent heat of the fuel. The heat transfer coefficient $\alpha$ is given by empirical functions that have been formulated from experimental investigations that employed a pintle injector and $n$-pentane [15]:

$$
\begin{aligned}
& \alpha=760 \Delta T^{0.26} \text { when } 0 \leq \Delta T \leq 5 \\
& \alpha=27 \Delta T^{2.33} \text { when } 5 \leq \Delta T \leq 25 \\
& \alpha=13800 \Delta T^{0.39} \text { when } \Delta T \geq 25
\end{aligned}
$$

in $\mathrm{W} / \mathrm{m}^{2} \mathrm{~K}$. The degree of superheat is calculated using the boiling temperature of the fuel at the specific ambient pressure, defined as:

$$
\Delta T=T_{d}-T_{b}
$$

where $T_{b}$ is the boiling tem

perature and $T_{d}$ the instantaneous droplet temperature. A vapor film surrounding the droplet is incorporated into the evaporation equations, this vapor film is calculated based on the mixture fraction of fuel vapor and ambient air properties.
This vapor film incorporates the reduction in the rate of evaporation with an increase in partial vapor pressure (caused by a vapor film subsiding in the immediate area surrounding the droplet).

The total evaporation rate $M_{t}$ is calculated by the accumulation of the subcooled, $M_{s c 1}$ or $M_{s c 2}$, and superheated, $M_{s h}$, evaporation rates, i.e.:

$$
\frac{d M_{t}}{d t}=\frac{d M_{s c 1}}{d t}+\frac{d M_{s h}}{d t}
$$

It should be noted that at subcooled conditions the superheat evaporation term is equal to zero. The additional evaporation caused by internal droplet heat transfer increases linearly with superheat degree, and the heat transfer coefficient increases non-linearly at three specific superheat degrees, resulting in an ever increasing non-linear superheat evaporation rate.

An increased mass transfer rate due to flash-boiling subsequently causes an increase in heat transfer. The conservation of energy law is used to determine the heat transfer of the dispersed phase at both non flashing and flashing conditions, whereby heat transfer is calculated directly from surface heat transfer and phase-change mass transfer:

$$
m C_{p} \frac{d T_{d}}{d t}=-A h\left(T_{d}-T\right)+H_{V}\left(\frac{d M_{T}}{d t}\right)
$$

where $h$ is the heat transfer coefficient which is a function of the Nusselt number, originally derived by Wakil et al. [30] and $T$ is the ambient gas temperature.

\section{Droplet Break-Up and Collision Models}

\section{Droplet Break-Up}

In order to model droplet break up, an essential part of atomizing sprays, the Reitz-Diwakar droplet break-up model was applied [31]. Two break-up regimes are modelled, namely bag break-up and stripping break-up, both of which are caused by aerodynamic forces acting upon the droplet surface. Using non-dimensional values, namely the Weber and Reynolds numbers (documented in Appendix A), and empirical model constants, the onset of droplet break-up is determined and modelled. The overall break-up rate is calculated as a function of the stable droplet diameter, which is a droplet diameter that can withstand the current aerodynamic forces acting upon it, remaining intact. A breakup timescale is also incorporated along with the instantaneous droplet diameter. The break-up rate is given in Equation 9.

$$
\frac{d D_{t}}{d t}=\frac{D_{d}-D_{d, \text { stable }}}{\tau_{b}}
$$

Page 4 of 23 
Here $\tau_{b}$ is the break-up timescale, $D_{d}$ the instantaneous droplet diameter and $D_{d, \text { stable }}$ the stable droplet diameter. The stable droplet diameter and break-up timescales are calculated separately for each regime and compete where the smallest values are applied in order to calculate the break-up rate. The equations used in both the bag break-up and stripping breakup are as follows [31]:

Bag break-up:

$$
\begin{gathered}
W e=\frac{\rho\left|u-u_{d}\right|^{2} D_{d, \text { stable }}}{2 \sigma_{d}} \geq C_{b 1} \\
\tau_{b}=\frac{C_{b 2} \rho_{d}^{1 / 2} D_{d}^{3 / 2}}{4 \sigma_{d}^{1 / 2}}
\end{gathered}
$$

Stripping break-up:

$$
\begin{gathered}
\frac{W e}{\sqrt{R e}} \geq C_{s 1} \\
\tau_{b}=\frac{C_{s 2}}{2} \sqrt{\left(\frac{\rho_{d}}{\rho}\right)} \frac{D_{d}}{\left|u-u_{d}\right|}
\end{gathered}
$$

The stable droplet diameter and break-up timescale for each regime are calculated based on the empirical constants $C_{b 1}$, $C_{s 1}, C_{b 2}$ and $C_{s 2}$ derived by Reitz and Diwakar [31], the default values are displayed in Table 1 .

Table 1. Reitz-Diwakar droplet break-up model constants.

\begin{tabular}{|c|c|c|c|}
\hline $\mathrm{C}_{\mathrm{b} 1}$ & $\mathrm{C}_{\mathrm{s} 1}$ & $\mathrm{C}_{\mathrm{b} 2}$ & $\mathrm{C}_{\mathrm{s} 2}$ \\
\hline 6 & 0.5 & 3.1416 & 20 \\
\hline
\end{tabular}

The influence of the model constant values of $\mathrm{C}_{\mathrm{b} 1}$ and $\mathrm{C}_{\mathrm{b} 2}$ on spray characteristics are also investigated in the current paper.

\section{$\underline{\text { Droplet Collisions }}$}

Droplet collisions are modelled based on O'Rourke's statistical approach [32] with a "speed up" algorithm developed by Schmidt and Rutland [33]. Two fundamental conditions must be met if droplets are to collide [34]. The first is that the droplets must be moving towards each other, stated in the following equation:

$$
U_{1,2}=\left(u_{1}-u_{2}\right) \frac{X_{2}-X_{1}}{\left|X_{2}-X_{1}\right|}
$$

where $U_{1,2}$ is the relative velocity between two droplets, $u_{1}$ and $u_{2}$ are droplet velocity vectors and $X_{1}$ and $X_{2}$ are the droplet position vectors. The second condition is that the droplets Page 5 of 23 must be moving at a speed which results in a relative displacement (within one time step) equal to or greater than the distance between them. Which is numerically described as follows:

$$
K U_{1,2} \Delta t>\left|X_{2}-X_{1}\right|-\left(r_{1}+r_{2}\right)
$$

where $K$ is the relative motion factor (set to the default value of unity in this investigation), $\Delta t$ is the time step and $r_{1}$ and $r_{2}$ are the radii of the droplets. If these are not met, collisions may not occur within the current time step. If these two prerequisites are met, then a statistical approach is applied where droplets may collide. The statistical approach assumes droplets are distributed evenly over the entire cell and a Poisson distribution is applied in determining the number of collisions occurring in the current time step.

Once the number of collisions have been calculated, the most appropriate regime is selected via the droplet Weber number. Three regimes are available namely: coalescence, separation and bouncing. The bouncing regime models two droplets which do not coalesce, instead they are considered as two solid spheres which collide, exchanging only momentum with no restitution factor. In the case of separation, momentum is also only exchanged. However, this regime is used to model two droplets which coalesce but possess too great a momentum to permanently remain attached, hence the droplets separate. Coalescence is where two droplets collide and coalesce to form a single larger droplet, here momentum, mass and energy are exchanged.

O'Rourke's [32] droplet-droplet collision model can be improved by inclusion of submodels for further modes of collision that have been found beneficial to the prediction of dense diesel sprays [35]. However, this was not considered necessary within the immediate objectives of the current study, albeit part of our work in progress for the gasoline injection system under study here.

\section{Simulation Setup}

A cubic domain of $80 \mathrm{~mm}^{3}$ was created and a grid consisting of hexahedral elements was produced. A number of cell sizes ranging from $0.5 \mathrm{~mm}$ to $3 \mathrm{~mm}$ in size were studied to identify an optimum resolution for this grid. The final resolution was considered on the basis of limitations associated with the LPT; specifically, this requires a sufficient resolution for the assumption that a Lagrangian parcel displaces no Eulerian phase to remain applicable. This assumption is acceptable when the volume fraction of the dispersed phase is kept relatively small. In order to do this a cell size of $1 \mathrm{~mm}$ was chosen as cells of $\leq 0.5 \mathrm{~mm}$ tend to generate an unstable simulation as the volume fraction limit of 0.4 could be reached in the dense regions of the spray. $1 \mathrm{~mm}$ cells were also compatible with the future application of the methodology to engine simulations, where $1 \mathrm{~mm}$ cells have been deemed small enough for in-cylinder flow simulations (e.g. when validated 
against PIV data [21]) and they also allowed reasonable CPU times within the computational power bounds available to the authors. Therefore, finally, 512000 cells of $1 \mathrm{~mm}$ size filled the computational domain and an initially quiescent environment of dried air at $T_{\infty}=20^{\circ} \mathrm{C}$ was considered. A time step of $1 \mu$ s was employed. This selection was again based on future application to engine simulations and computational power availability; for reference, $1 \mu$ s corresponds to $\sim 0.01$ crank angle degree (CAD) resolution at 1500 RPM.

The simulations were set up on the basis of an asymmetric sixhole gasoline injector, displayed with full geometrical details in Appendix B. The injector consisted of six holes each of 200 $\mu \mathrm{m}$ in internal diameter and individual plume cone angles $\theta$ of about $15^{\circ}$. A large database of spray images is available with this injector with various fuels for validation purposes (including gasoline, alcohols, high and medium volatility hydrocarbon components, etc.), both in quiescent injection chambers and in-cylinder [9], [36]. A constant mass flow rate of $20 \mathrm{~g} / \mathrm{s}$ was used throughout the test cases of the current study. This was measured for the same injection system at an injection pressure, $P_{i n j}$ of $150 \mathrm{bar}$, e.g. see [25], [26]. A variation in mass flow rate of less than $5 \%$ was seen in the experimental data at varying ambient conditions, hence it was decided to fix the flow rate at all conditions within the bounds of the current study. Table 2 displays all test cases used in the current modelling study.

Table 2. Non flash-boiling and flash-boiling spray cases.

\begin{tabular}{|c|c|c|c|c|c|}
\hline $\begin{array}{c}\text { Spray } \\
\text { No. }\end{array}$ & $T_{f}\left[{ }^{\circ} \mathrm{C}\right]$ & $P_{\infty}[\mathrm{bar}]$ & Fuel & $T_{b}\left[{ }^{\circ} \mathrm{C}\right]$ & $\Delta T\left[{ }^{\circ} \mathrm{C}\right]$ \\
\hline 1 & 20 & 1.0 & $n$-Pentane & 36.1 & 0.0 \\
\hline 2 & 20 & 1.0 & iso-Octane & 99.0 & 0.0 \\
\hline 3 & 120 & 1.0 & $n$-Pentane & 36.1 & 83.9 \\
\hline 4 & 120 & 1.0 & iso-Octane & 99.0 & 21.0 \\
\hline 5 & 90 & 1.0 & $n$-Pentane & 36.1 & 53.9 \\
\hline 6 & 120 & 0.5 & $n$-Pentane & 16.0 & 104.0 \\
\hline 7 & 120 & 0.5 & $i$ iso-Octane & 78.0 & 42.0 \\
\hline 8 & 90 & 0.5 & $n$-Pentane & 16.0 & 74.0 \\
\hline 9 & 180 & 0.3 & $n$-Pentane & 3.0 & 177.0 \\
\hline 10 & 180 & 0.3 & iso-Octane & 62.0 & 117.0 \\
\hline
\end{tabular}

\section{RESULTS AND DISCUSSION}

\section{Subcooled Conditions}

The two evaporation model terms $M_{s c 1}$ and $M_{s c 2}$ (Equations 1 and 2) were compared and validated both quantitatively and qualitatively at subcooled conditions against experimental data

Page 6 of 23 obtained using the same nozzle set-up. Specifically, the spray predictions were compared to spray images obtained by highspeed shadowgraphy and Mie scattering techniques, as well as against penetration lengths obtained by image processing [10], [36]. Both evaporation models were quantitatively compared using two fuels, namely iso-Octane and $n$-Pentane. The two models produced very similar fuel sprays with almost identical characteristics at subcooled conditions; their droplet diameters and spray penetrations had a difference in the region of $2 \%$. No contribution existed from the superheated evaporation term $M_{\text {sh }}$ (Equation 4) as this was equal to zero at subcooled conditions. From here on the results presented correspond to the total evaporation term $M_{t}$ that incorporated $M_{s c 1}$ and $M_{s h}$, unless otherwise stated. Figure 2 displays a comparison between the results of the computational model and spray images at subcooled conditions of $P_{\infty}=1.0$ bar and $T_{f}=20^{\circ} \mathrm{C}$ for both iso-Octane and $n$-Pentane fuels. It can be observed that the numerical model was able to reproduce quite well the general spray characteristics and shape of spray plumes.
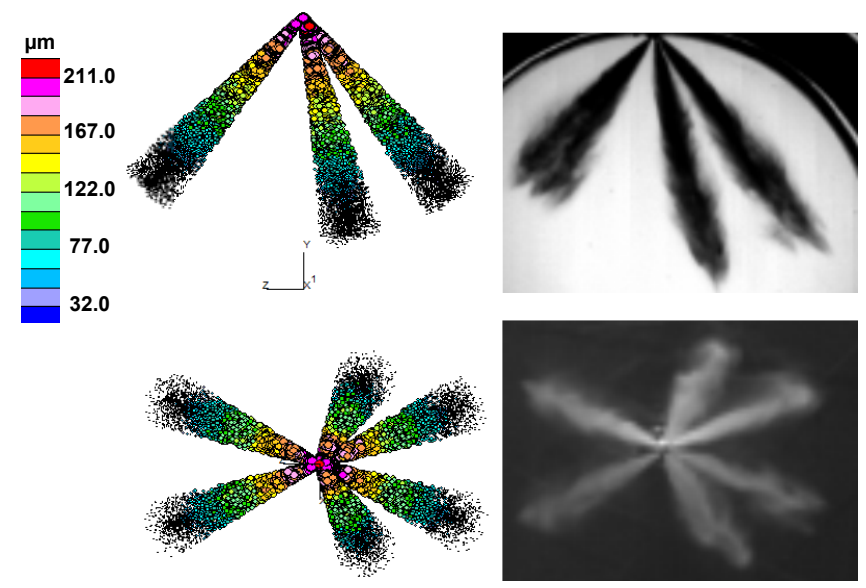

iso-Octane
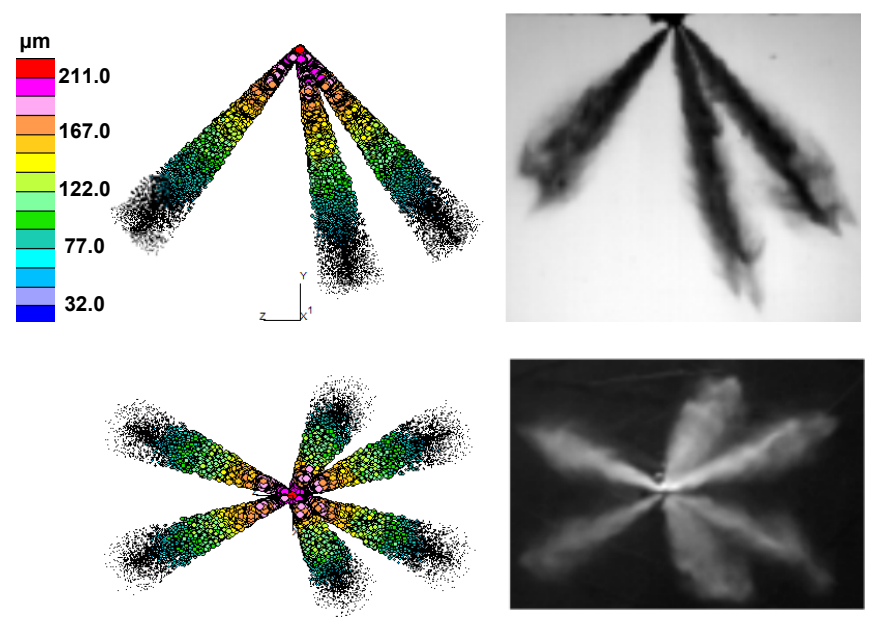

n-Pentane

Figure 2. Computational spray results and experimental spray images of iso-Octane and n-Pentane at $P_{\infty}=1.0$ bar and $T_{f}=20^{\circ} \mathrm{C}$. 
To study the effects of fuel on predicted spray characteristics at subcooled conditions, a direct comparison is made between the highly volatile $n$-Pentane and the lower volatility isoOctane. The size and density of droplets at the tips of all the spray plumes in Figure 2 are different between the two fuels, with $n$-Pentane exhibiting smaller droplets. The predicted sauter mean diameter (SMD) of the droplets during injection is compared for the two fuels in Figure 3. The difference in SMD between the two fuels at $400 \mu \mathrm{s}$ after start of injection (ASOI) is found to be $10.2 \mu \mathrm{m}$. The higher volatility of $n$ Pentane results in faster evaporation as well as a smaller stable droplet size. The higher evaporation rates associated with $n$ Pentane can be seen in Figure 4, where fuel vapor mass fraction is plotted on the central axis of the injector. The effect of fuel properties is clearly displayed, with iso-Octane producing a vapor mass fraction of approximately $2 \%$ of that produced by $n$-Pentane.

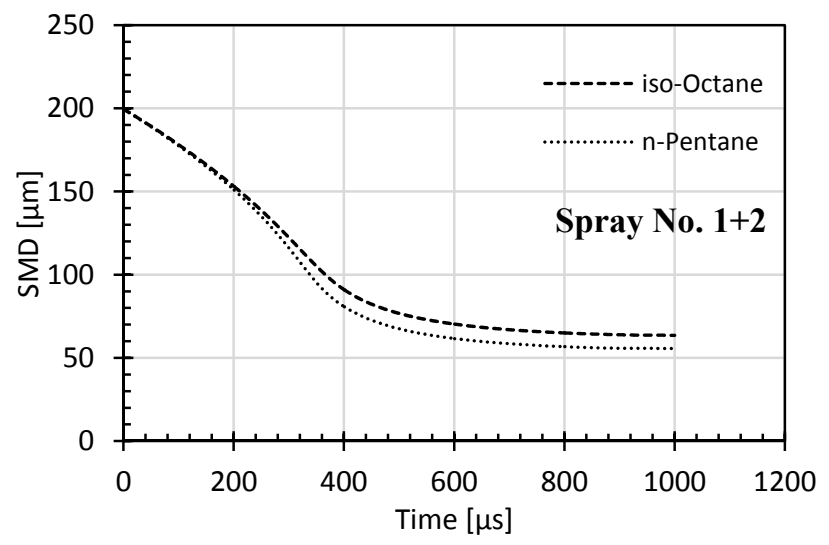

Figure 3. SMD of n-Pentane and iso-Octane at $P_{\infty}=1.0 \mathrm{bar}$ and $T_{f}=20^{\circ} \mathrm{C}$.
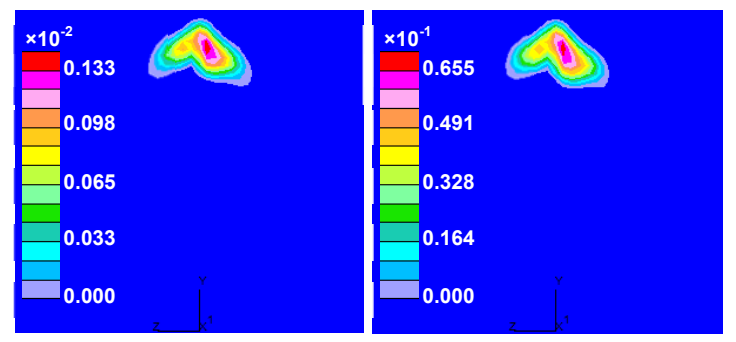

Figure 4. Vapor mass fraction of iso-Octane (left) and $n$ Pentane (right) at $P_{\infty}=1.0$ bar and $T_{f}=20^{\circ} \mathrm{C}$.

The newly implemented evaporation model with flash-boiling capabilities was further validated at subcooled conditions by comparing the penetration length of plumes 1 and 6 (see Appendix B for reference) to experimental data. The penetration is calculated by importing individual parcel geometry into an in-house MATLAB code. The penetration was calculated at multiple time steps, and was directly compared to experimental data as shown in Figure 5. The reader should be aware that the computational results have been modified to incorporate the injection delay witnessed in Page 7 of 23 experiments, this was achieved by including the injector driver's delay duration (typically around $300 \mu \mathrm{s}$ ) to the computational results [37].

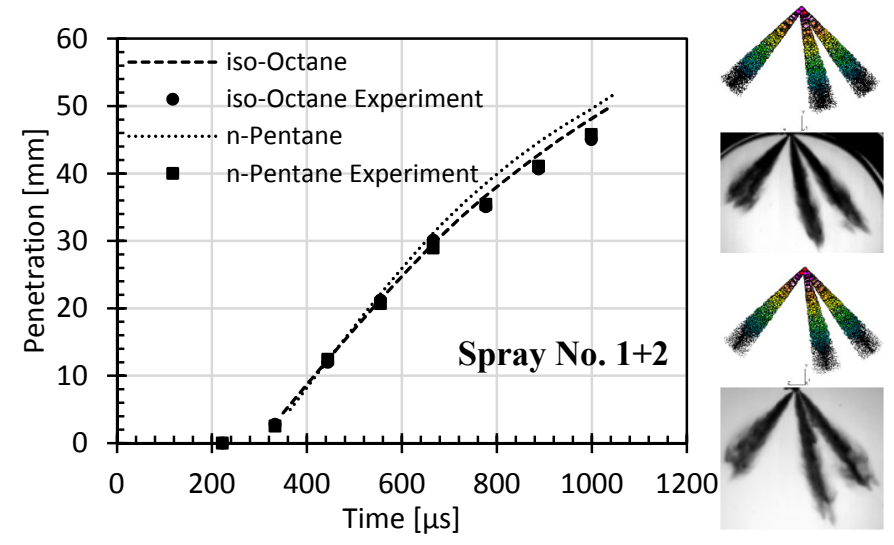

Figure 5. Plume penetration of n-Pentane and iso-Octane at $P_{\infty}=1.0$ bar and $T_{f}=20^{\circ} \mathrm{C}$.

The computational penetration curves displayed in Figure 5, for both $n$-Pentane and iso-Octane fuels contain a difference to experiment of $10 \%$ and $3 \%$ at $800 \mu \mathrm{s}$ ASOI, respectively. It should be noted here that the initial injection velocity of each fuel is different, due to a constant mass flow rate being applied and fuel properties varying. The injection velocities at this condition are $91.64 \mathrm{~ms}^{-1}$ and $101.60 \mathrm{~ms}^{-1}$ for iso-Octane and $n$ Pentane, respectively, producing higher penetrations for $n$ Pentane. The relatively small difference in penetration length gives confidence in the implementation of the evaporation model and accuracy of the simulation set-up. A similarly small difference was quantified during experimentation and the experimental spray penetration curves reflect this difference.

It is noted here that, in order for the predicted penetrations to precisely match those of the experiments, the break-up model constants and initial droplet properties could be tweaked. This was examined systematically and is documented in the following sections.

\section{Break-up Model}

The Reitz-Diwakar [31] droplet break-up model relies on the calculation of a stable droplet diameter to predict droplet break-up by aerodynamic forces. The calculations ultimately rely on fuel properties, pressures and temperatures, which can result in the default model constants being unsuitable, especially at extreme conditions corresponding to superheated liquids in the case of high-pressure fuel injection. Razzaghi [38] studied the effect of superheating on the break-up of a flashing spray, determining a critical superheat degree whereby break-up due to thermal mechanisms dominate. It is this conclusion which suggests that the break-up model can be a significant and useful tool in building a numerical framework capable of predicting suitable droplet sizes and spray characteristics of a flash-boiling spray. However, the 
aim of this investigation is to define the potential to replicate the enhanced droplet break-up from thermal effects, in a flashboiling spray. The influence of break-up model coefficients on spray formation, of which are documented in Table 1, were studied at subcooled conditions. Both the bag break-up and stripping break-up weber number constants were adjusted simultaneously, ultimately resulting in a steady reduction in stable droplet diameter. The break-up timescale constants $\left(C_{b 2}\right.$ and $C_{s 2}$ ) were kept unchanged at the default values to give a direct comparison between stable droplet diameters. Figure 6 represents the plume penetration with reducing model constants from the default values given by Reitz and Diwakar [31]. A clear effect on the plume penetration was observed, whereby a smaller stable droplet diameter followed an expected trend, producing a spray with smaller droplets. An exact match between the numerical solution and experimental data can be achieved through adjusting the droplet break-up model constants. However, this trial and error approach is not always applicable.

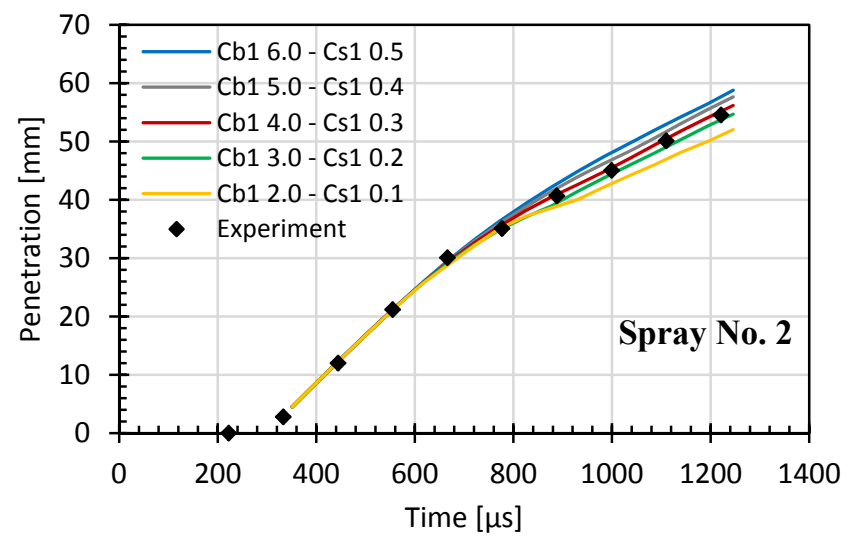

Figure 6. Effect of break-up model constants on plume penetration of iso-Octane at $P_{\infty}=1.0 \mathrm{bar}, \mathrm{T}_{f}=20^{\circ} \mathrm{C}$.

Flash-boiling sprays produce significantly smaller droplets when compared to non-flashing sprays, a byproduct of both high evaporation rates and enhanced aerodynamic break-up due to fuel properties (such as surface tension and viscosity), diminishing with temperature. A superheated flash-boiling spray may also contain a thermal break-up mechanism caused by bubble nucleation and growth inside of liquid droplets, which is currently not implemented into the current computational framework. The reduction in SMD caused by a reduction in break-up criterion is displayed in Figure 7. The SMD is reduced from $57.2 \mu \mathrm{m}$ to $24.7 \mu \mathrm{m}$ at $1000 \mu \mathrm{s}$ ASOI when using the outer-most values, a trend which can commonly occur in flash-boiling sprays due to the enhanced break-up mechanism. The value associated with the break-up timescale was clearly visible from the SMD plot of Figure 7, as the inception of break-up occurred at approximately $200 \mu \mathrm{s}$, where the effect of model constants became prominent. For completeness, it is noted here that the SMD of iso-Octane's spray droplets measured at a location of $20 \mathrm{~mm}$ from the nozzle exit within plume 1 using phase Doppler anemometry was of the order $15-20 \mu \mathrm{m}$ at $20^{\circ} \mathrm{C}, 1.0$ bar, i.e. closer to the lower end of predicted values in Figure 7.

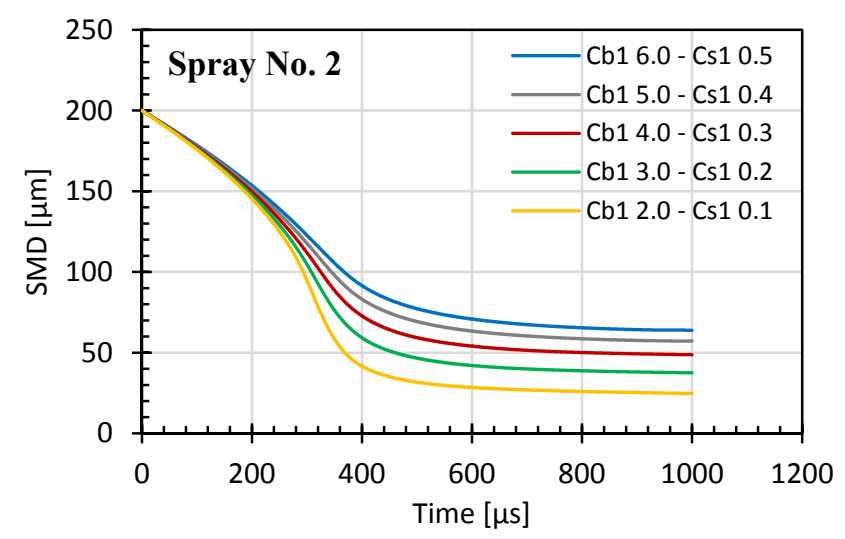

Figure 7. Effect of break-up model constants on the SMD of iso-Octane at $P_{\infty}=1.0$ bar and $T_{f}=20^{\circ} \mathrm{C}$.

The capability of modifying current break-up models to replicate enhanced thermal break-up mechanisms is a potential solution in advancing the computational framework towards an accurate flash-boiling numerical model. This may well involve the Jakob number to include superheat effects. Inclusion of such effects was not part of the immediate objectives of the current study, neither was tuning of the default break-up model constants to match the experimental curves over a range of superheated conditions, since that would be a purely practical tuning exercise without much sophistication. Therefore, with the acquired knowledge of sensitivity to these constants for the injector under study, it was decided to use the defaults constants, as listed in Table 1, for the rest of the work. This was to maintain universality by decoupling tuning effects from any fundamental understanding that could be gained. It is envisaged though that the knowledge gained from this section and subsequent ones will be applied to future refinement of the developed code.

\section{Flash-Boiling Sprays}

The current section investigates the behavior of the flashboiling evaporation model at superheated flash-boiling conditions. Firstly, an initial comparison was made between spray predictions and experiments obtained from the literature where a Laser-induced Exciplex fluorescence (LIEF) technique was used to visualise the vapor phase in a similar multi-hole gasoline injector to that used in the current study [39]. It was found that the vapor phase produced with the implemented superheated evaporation term was qualitatively comparable to that measured by the LIEF experiments, with clear dependency on fuel type (however, this is not shown for brevity due to the qualitative nature of the comparison and the exact experimental injector geometry of LIEF being unknown). Then a second investigation was carried out to observe the results obtained with the two subcooled evaporation models, $M_{s c 1}$ and $M_{s c 2}$, and with the total 
evaporation flash-boiling model, $M_{t}$ (with $M_{S c 1}$ contribution), and at conditions equivalent to the available in-house experimental spray data. Various conditions were modelled using both $n$-Pentane and iso-Octane, ranging from superheat conditions of $83.9^{\circ} \mathrm{C}$ and $21.0^{\circ} \mathrm{C}$ respectively (Spray No. 5 and 6) to severe superheat conditions of $165^{\circ} \mathrm{C}$ and $111.0^{\circ} \mathrm{C}$, respectively (Spray No. 11 and 12).

Specifically, conditions of initial fuel temperature of $T_{f}=120$ ${ }^{\circ} \mathrm{C}$ and atmospheric pressure of $P_{\infty}=1.0$ bar were initially used (Spray No. 5 and 6). A direct comparison between the total flash-boiling evaporation model $M_{t}$ and the two subcooled evaporation models $M_{s c 1}$ and $M_{s c 2}$ was made by plotting the vapor mass fraction of iso-Octane and $n$-Pentane at $400 \mu \mathrm{s} \mathrm{ASOI}$ on the central injector plane looking from the side, as illustrated in Figure 8. It is clear that the implemented superheat term produces a higher evaporation rate at superheated conditions in comparison to the subcooled models. The subcooled models produced vapor concentrations with comparable values, where $M_{s c 2}$ was seen to predict the smallest evaporation rate.
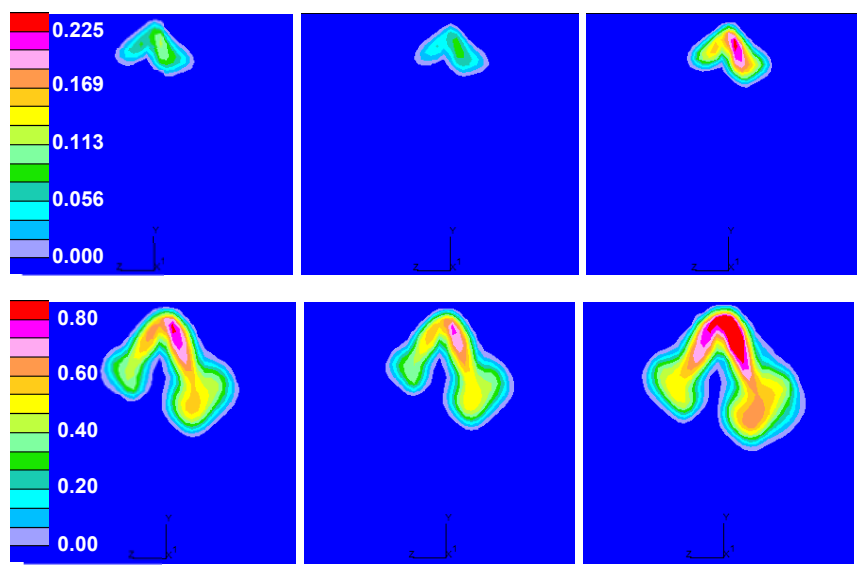

Figure 8. Vapor mass fraction of iso-Octane (top) and $n$ Pentane (bottom) at $T_{f}=120{ }^{\circ} \mathrm{C}$ and $P_{\infty}=1.0 \mathrm{bar}$, using $M_{s c 1}$ (left), $M_{s c 2}$ (center) and $M_{t}$ (right).

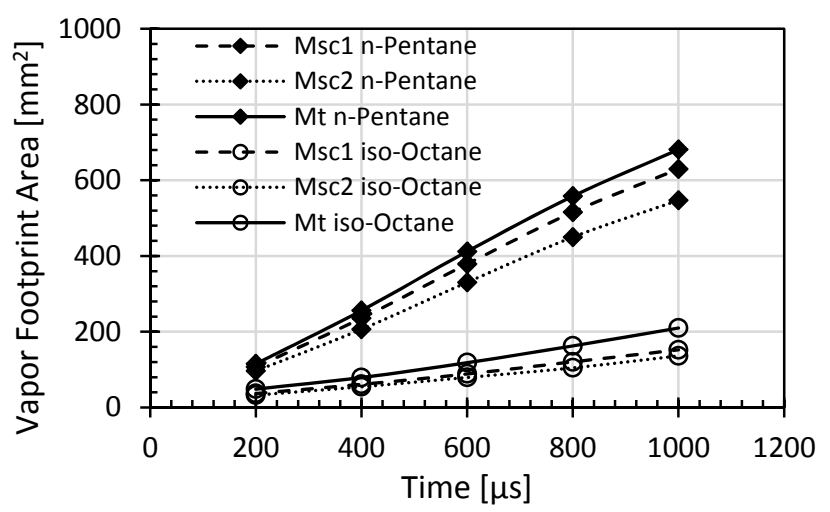

Figure 9. Vapor footprint area of iso-Octane and n-Pentane at $T_{f}=120^{\circ} \mathrm{C}$ and $P_{\infty}=1.0$ bar.
To quantify the effect of the added superheat evaporation term, the footprint area of the vapor phase on the central axis plane as shown in the vapor plots in Figure 8 is displayed in Figure 9. The more rapid evaporation at the beginning of injection predicted by the implemented superheat term, produced a larger footprint of vapor suggesting a promotion of homogeneity which is reported by Adachi et al. [15].

The increased mass of fuel in gaseous state at superheated expanded conditions could act as a potential source of promoting jet tip vortices (e.g. see [40] for a discussion on high-speed gaseous fuel jets), causing recirculation of vapor and a widening of the vapor footprint. This effect may also have an influence on spray collapse. At severe flashing the reduced inertia of small droplets produces a spray which is more susceptible to air entrainment, in turn increasing individual plume interactions, droplet collisions and spray collapse.

The velocity field of the Eulerian gas phase is plotted in Figure 10. The spray tip vortices are clearly visible in the twodimensional velocity vector plot of the Eulerian phase, which was plotted on the centerline of the injector relative to the side view. Vortices similar to that found in a PIV study by Zhang et al. [41] on a flash-boiling multi hole injector were found. Zhang et al. found that flashing produced stronger vortices in terms of velocity magnitude, and the increasing strength pushed the plumes towards the central axis, eventually contributing to collapse.

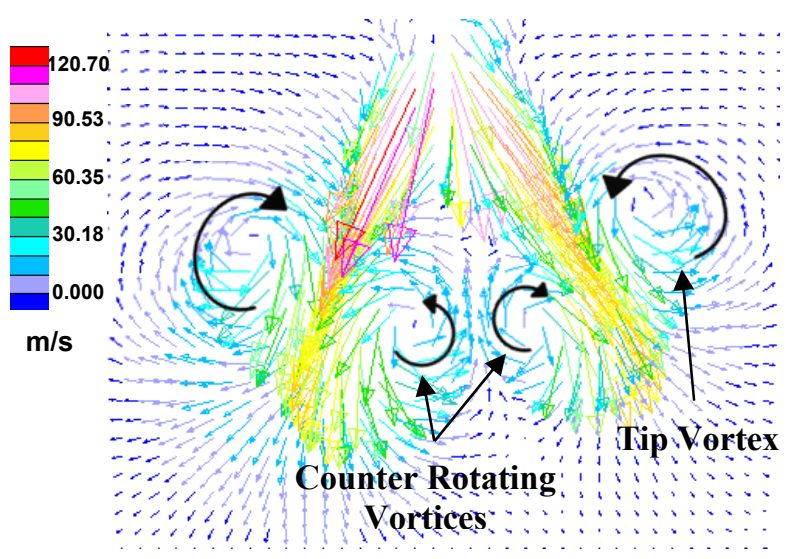

Figure 10. Side view of velocity vectors of the Eulerian phase, using $n$-Pentane at $T_{f}=120^{\circ} \mathrm{C}$ and $P_{\infty}=1.0$ bar.

The same vortex mechanism is captured in the Lagrangian particle tracking method employed here, however this technique may not be able to accurately model the tip vortices in the Eulerian phase, as the interaction between droplets and the surrounding vapor/air mixture are not directly resolved. Lagrangian/Eulerian momentum transfer was modeled with many limitations, such as perfectly spherical droplets, and momentum dissipation over the entire computational cell, resulting in a coarse representation and inaccurate dissipation of the Eulerian phase velocity. This limitation of the model may under-predict the strength of these vortices, potentially 
limiting the prediction of spray collapse with the current computational framework. Sher et al. [11] suggest that the vapor phase leaving the nozzle could have a velocity which is significantly higher than the liquid phase and could increase the velocity within the bulk spray surrounding.

The average droplet diameter of a flashing spray was found to be smaller than a non-flashing spray, due to the rapid evaporation upon exit of the nozzle. The SMD of the flashboiling evaporation model was compared to the subcooled model components and is illustrated in Figure 11.
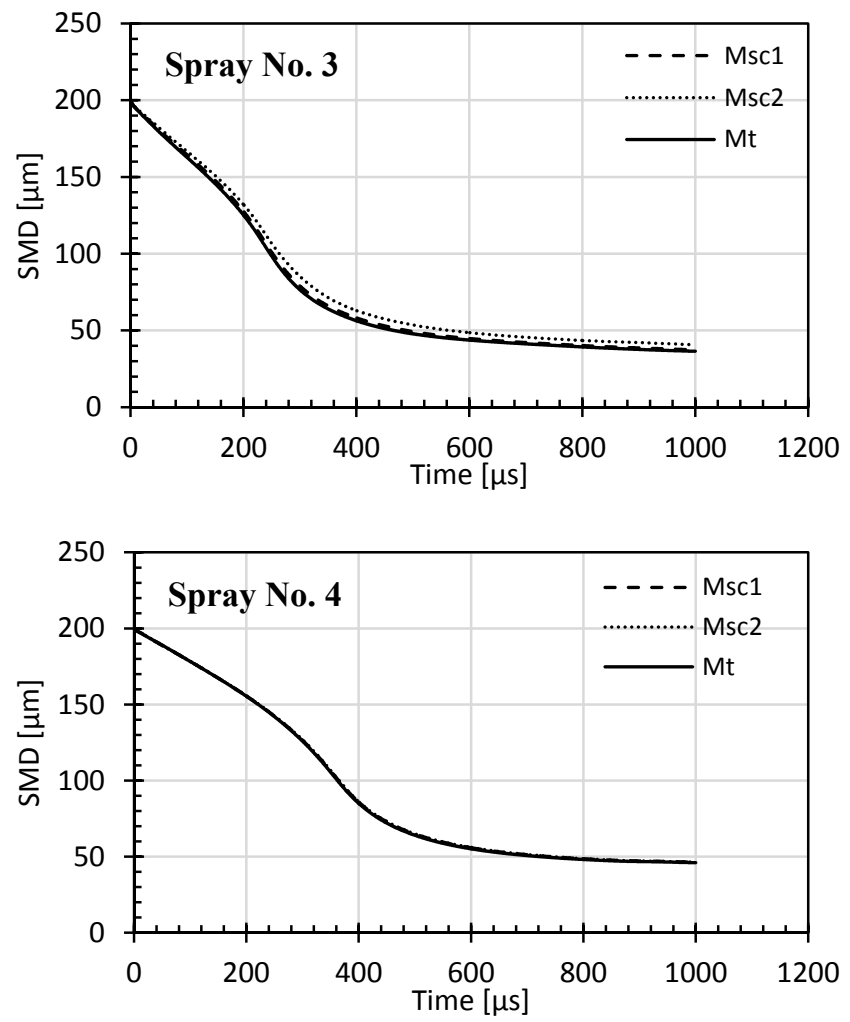

Figure 11. Comparison between the SMD of n-Pentane (top) and iso-Octane (bottom) at $P_{\infty}=1.0$ bar and $T_{f}=120^{\circ} \mathrm{C}$.

A reduction in SMD was observed for the flash-boiling model at the stated superheated conditions for $n$-Pentane. Specifically, an SMD at $400 \mu \mathrm{s}$ ASOI of $56.4 \mu \mathrm{m}$ was calculated, compared to $80.9 \mu \mathrm{m}$ at $20{ }^{\circ} \mathrm{C}$ shown earlier in Figure 3. This also illustrated the added contribution of the superheated droplet modelling term of the implemented total evaporation flash-boiling model, where the additional heattransfer from superheat contributed to surface evaporation and further reduction in droplet size. Once the additional thermal energy was expended through surface evaporation, the droplet temperature fell below its boiling point. The evaporation rate then returned to its subcooled value, where the difference between the flash-boiling model and the subcooled models remained constant thereon. However, it is clearly noted that the contribution of the superheated evaporation term, using the published empirical constants, is not as disruptively large as one may have initially expected for a high volatility fuel like $n$-Pentane. In the case of iso-Octane the effect of the implementation of a flash-boiling evaporation term appeared insignificant at the much lower degree of superheat experienced by this fuel at these conditions.

The penetration lengths of plumes 1 and 6 are displayed in Figure 12 for both $n$-Pentane and iso-Octane fuels with superheat of $83.9{ }^{\circ} \mathrm{C}$ and $21.0{ }^{\circ} \mathrm{C}$, respectively (Spray No. 5 and 6).
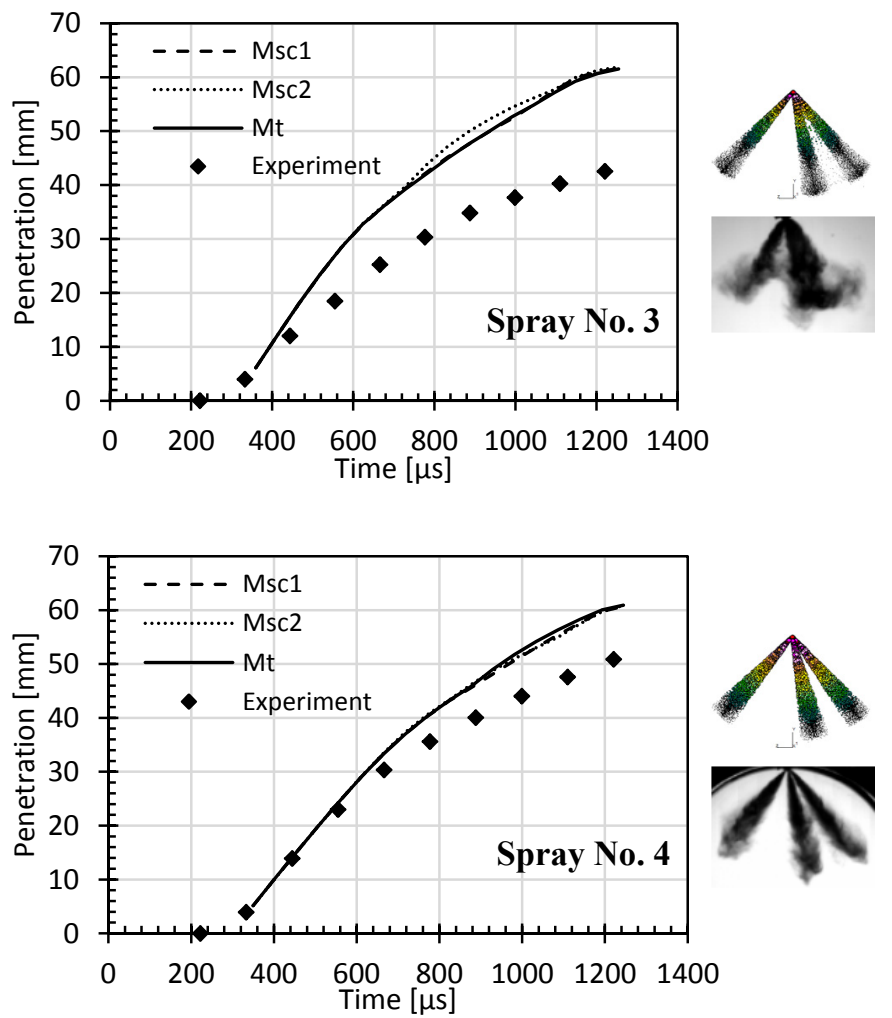

Figure 12. Plume penetration of n-Pentane (top) and isoOctane (bottom) at $P_{\infty}=1.0$ bar and $T_{f}=120^{\circ} \mathrm{C}$ using $M_{s c 1}$, $M_{s c 2}$ and $M_{t}$ in comparison to experiments.

It can be seen that for these flash-boiling conditions, the flashboiling evaporation model $M_{t}$ caused a small reduction in penetration for $n$-Pentane in comparison to $M_{s c 2}$ only, pushing the predicted results closer to the experiment, but only by a little. This is clearly a deficiency; more to the point, it is noted that the experiments showed a degree of spray collapse, as displayed in the spray image adjacent to Figure 12, but no type of such spray collapse behavior was predicted using the existing model settings. In the case of iso-Octane where the superheat degree did not breach the highest criteria in the calculation of the heat transfer coefficient of Equation (5), no significant effect of the additional evaporation term was observed. Here the experiments showed no spray collapse which allowed the computational penetration to lie overall closer to the experiment (small discrepancies between $M_{t}$ and $M_{s c}$ terms past $1 \mathrm{~ms}$ ASOI stem from the prediction of isolated

Page 10 of 23 
single large droplets at the tip of spray plume and require further study). Another interesting observation is the difference between $M_{s c 1}$ and $M_{s c 2}$ at superheated conditions. The evaporation limit of $M_{s c 2}$ is lower than that of $\mathrm{M}_{s c 1}$, displayed as larger SMD values, and larger penetration lengths for $n$-Pentane. The variance comes from differences in the formulation, where a smaller saturated evaporation limit is seen for $M_{S c 2}$.
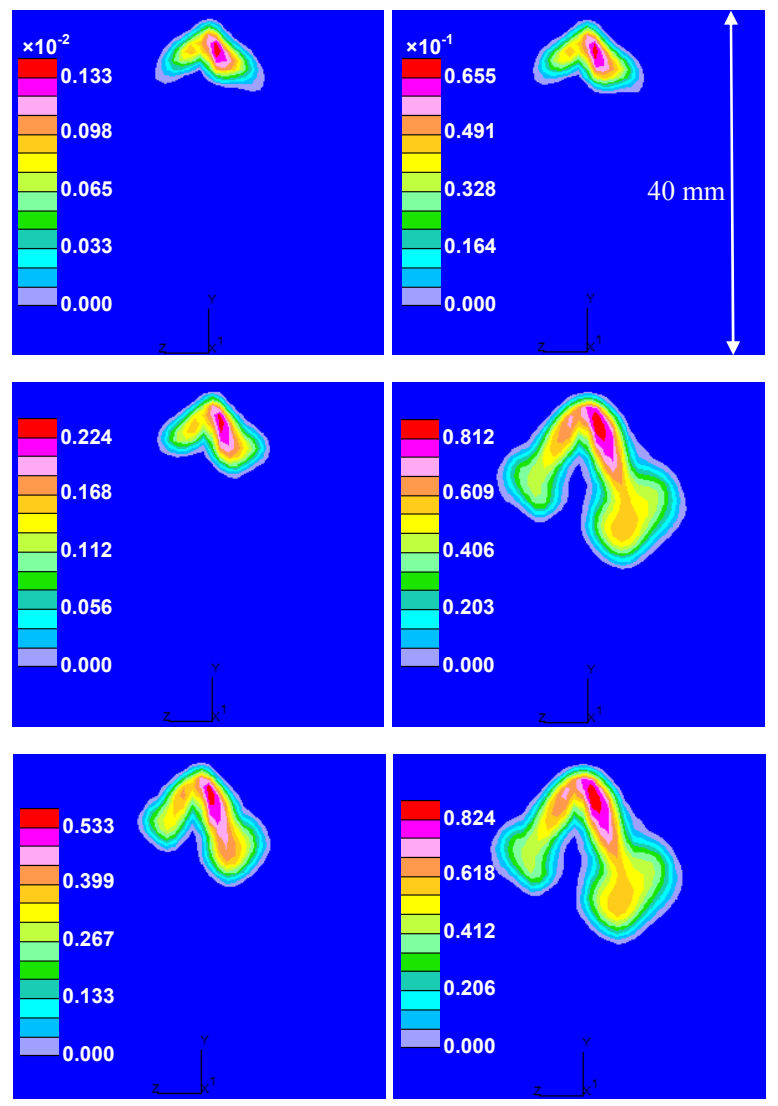

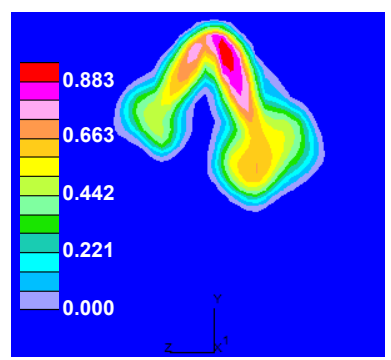

iso-Octane

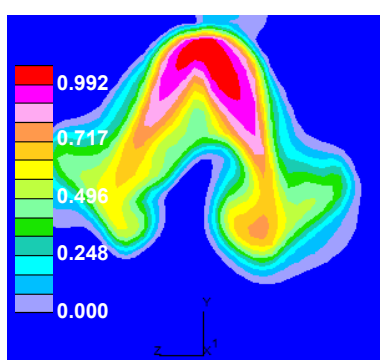

n-Pentane
Figure 13. Vapor mass fraction of iso-Octane (left) and $n$ Pentane (right) at $T_{f}=20^{\circ} \mathrm{C}$ and $P_{\infty}=1.0 \mathrm{bar}, \mathrm{T}_{f}=120^{\circ} \mathrm{C}$ and $P_{\infty}=0.5$ bar, $T_{f}=120^{\circ} \mathrm{C}$ and $P_{\infty}=0.5$ bar and $T_{f}=180$ ${ }^{\circ} \mathrm{C}$ and $P_{\infty}=0.3$ bar.

To study the effect of injection temperature and ambient pressure on evaporation, the vapor mass fraction was plotted at numerous conditions using both fuels (Spray No. 1, 2, 3, 4, $6,7,9$ and 10). This was carried out by varying the fuel injection temperature and ambient pressure separately. The vapor mass fractions at $400 \mu \mathrm{s}$ ASOI are displayed in Figure 13 , which are plotted on a plane cutting through the central axis of the injector.

The addition of a flash-boiling evaporation model was implemented and the limitation of the current computational framework was apparent, where complex spray structures in the form of plume merging and collapse could not be predicted with the chosen settings. In order to further investigate this limitation a sensitivity study of the results to the initial droplet size and plume angle, as well as the empirical constants of the superheated heat transfer parameter of Equation (5), was carried out as detailed in the next section.

\section{Parametric Studies}

\section{$\underline{\text { Initial Droplet Diameter }}$}

Droplet-droplet collision models can significantly influence the spray predicted by the numerical code and the number and type of collisions can vary depending on spray properties. Superheated sprays were modelled and the initial droplet diameter and individual spray plume angle were varied independently in order to attempt to predict the interaction between individual plumes. The proximity of individual plumes of multi-hole injector can hugely influence the subsequent spray formation, as inter-plume interactions can produce merged plumes, in-turn producing a 'collapsing' spray and complex droplet cloud structures [10], [42] that can subsequently affect in-cylinder mixing, wall wetting, combustion and emissions.

The flash-boiling phenomena can reside both internally and externally in the region of the nozzle orifice, depending on a number of factors including in-nozzle and atmospheric conditions, as well as fuel properties [8], [25]. At high superheat degrees, the spray is deemed to be fully flashing as the flow exiting the nozzle can consist already of a large amount of fuel vapor cloud housing liquid droplets. The size of these liquid droplets diminishes as the severity of flashboiling increases, resulting in the initial droplet diameter becoming much smaller than the nozzle diameter for highly superheated fuels [12]. The influence of initial droplet size on spray formation was investigated for both $n$-Pentane and isoOctane at superheated conditions where the onset of plume merging was witnessed, $T_{f}=90{ }^{\circ} \mathrm{C}, P_{\infty}=1.0 \mathrm{bar}$, and $T_{f}=120$ ${ }^{\circ} \mathrm{C}, P_{\infty}=0.5$ bar, respectively. A number of initial droplet diameters were studied, ranging from the nozzle orifice of $D_{d}$ $=200 \mu \mathrm{m}$ down to $D_{d}=20 \mu \mathrm{m}$. The effect of those sizes on the spray formation of $n$-Pentane is displayed in Figure 15. It is clear that the initial droplet size influences the subsequent droplet momentum and droplet collisions mechanism, leading to gradual merging of the spray's plumes. Large initial droplets of $200 \mu \mathrm{m}$ produce no plume merging or spray collapse at these superheated conditions, whereas the smallest studied initial droplets of $20 \mu \mathrm{m}$ lead clearly to spray plumes fully merging. When compared to experiments, it seems that

Page 11 of 23 
there is an 'optimum' nominal initial droplet diameter that allows the computational framework to predict the global spray shape. Specifically, at these conditions, $100 \mu \mathrm{m}$ initial droplets lead to a degree of plume merging that agrees well with the experiment. In practice, to make such a 'reverseengineering' parametric exercise useful, a validated thermophysical relationship would need to be developed that would automatically predict the correct initial droplet diameter for a range of fuels and conditions.
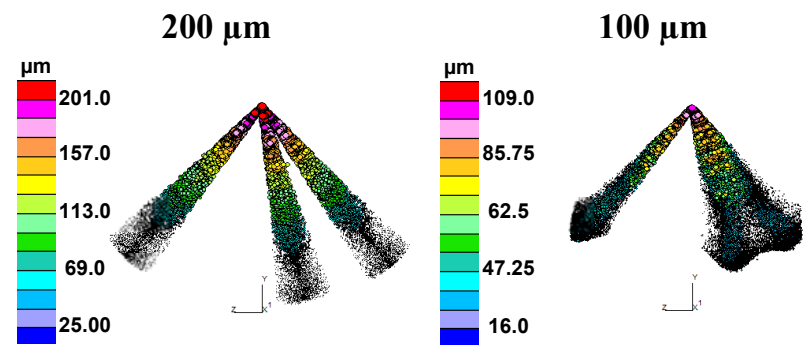

$50 \mu \mathrm{m}$

$20 \mu \mathrm{m}$
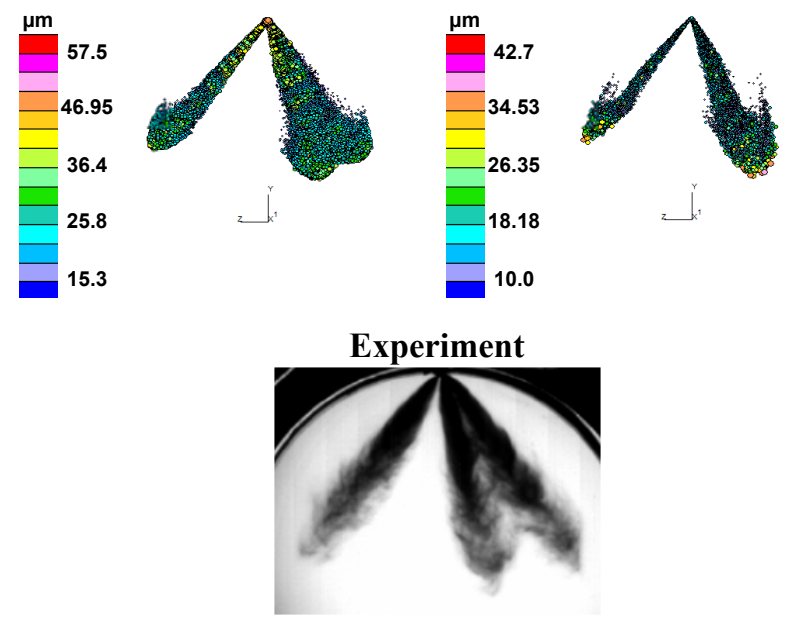

Figure 15. Spray formation of n-Pentane $C$ with varying initial droplet diameter at $P_{\infty}=1.0$ bar and $T_{f}=90^{\circ}$.

Another interesting finding from the current numerical study was the change in SMD over time of each spray, which is shown in Figure 17 for flashing $n$-Pentane. The initial SMD is typically equal to the initial droplet diameter. It was found that independent of initial droplet diameter, the SMD at $1000 \mu \mathrm{s}$ consisted of a small variation of $24.9 \mu \mathrm{m}$ between the largest and smallest initial droplet diameters. The small difference is caused by the larger, weaker droplets undergoing dropletbreakup as opposed to smaller more robust droplets residing under the stable droplet diameter limit. A slight increase in SMD can be seen for initial droplet sizes of $20 \mu \mathrm{m}$; this may be caused by some of these small initial droplets completely evaporating and remaining ones participating in droplet coalescence phenomena overcoming the reduction caused by evaporation.

The effect of initial droplet diameter on the spray characteristics was also investigated through plume penetration as displayed in Figure 16. It was found that the merging process caused by reduced initial droplet diameter resulted in a reduced plume penetration length. This effect is somewhat due to smaller droplets carrying less inertia, however, the collapsing mechanism also produces smaller penetrations because part of the droplets' axial velocity is converted into radial velocity from droplet interactions and the subsequent plume merging process.

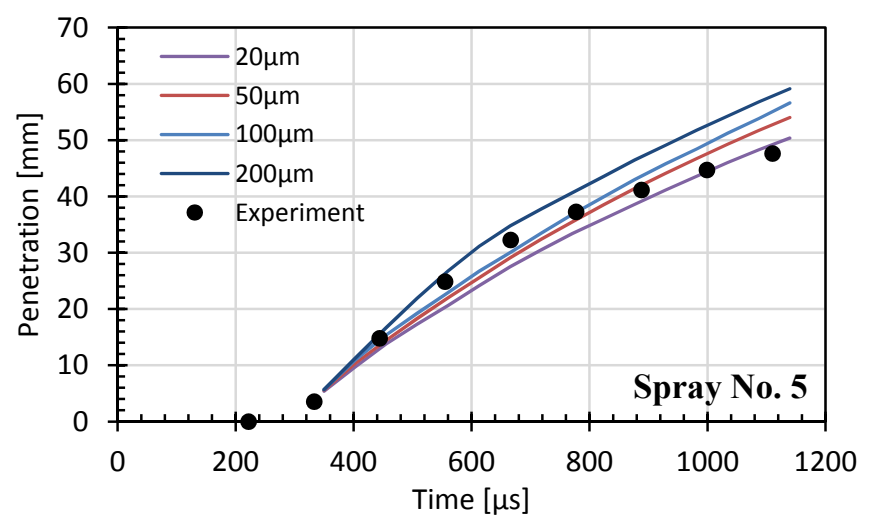

Figure 16. Penetration of n-Pentane with varying initial droplet diameter at $P_{\infty}=1.0$ bar and $T_{f}=90^{\circ} C$.

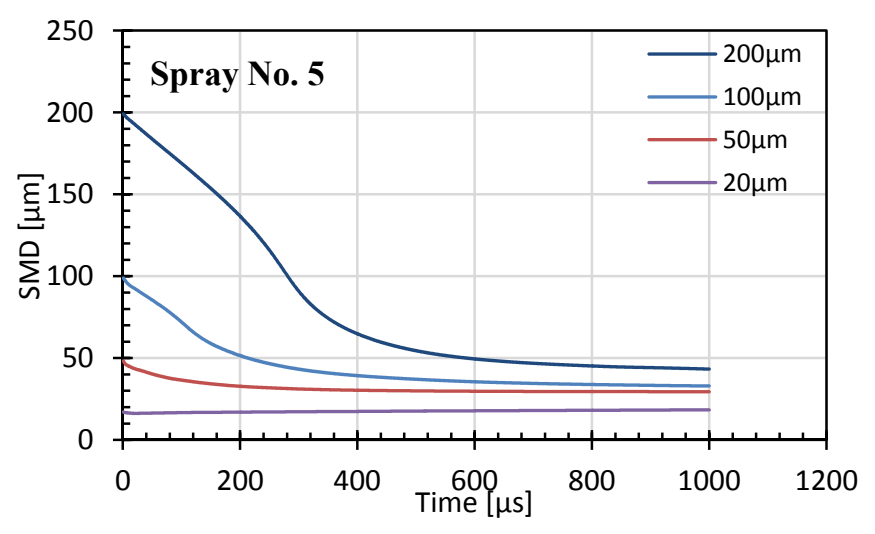

Figure 17. SMD of n-Pentane with varying initial droplet diameter at $P_{\infty}=1.0$ bar and $T_{f}=90{ }^{\circ} \mathrm{C}$.

The same effect of initial droplet diameter was apparent in isoOctane, however its lower volatility caused the effect to be somewhat retarded, due to the droplet evaporation rate being smaller and hence resulting in larger droplets downstream of the nozzle. The spray formation of iso-Octane is displayed in Figure 18. It can be seen that there is less recirculation of droplets at the leading edge, caused by the larger individual droplet mass as opposed to the $n$-Pentane spray case. In terms of penetration a very similar effect is found, where smaller droplets and plume merging produce a smaller plume penetration length, displayed in Figure 19. The SMD is displayed in Figure 20. A shallower gradient was produced in the case of iso-Octane fuel which is a clear indication of the smaller evaporation rate. The fuel is also less susceptible to break-up as it has a higher surface tension and viscosity, resulting in a larger stable droplet diameter.

Page 12 of 23 

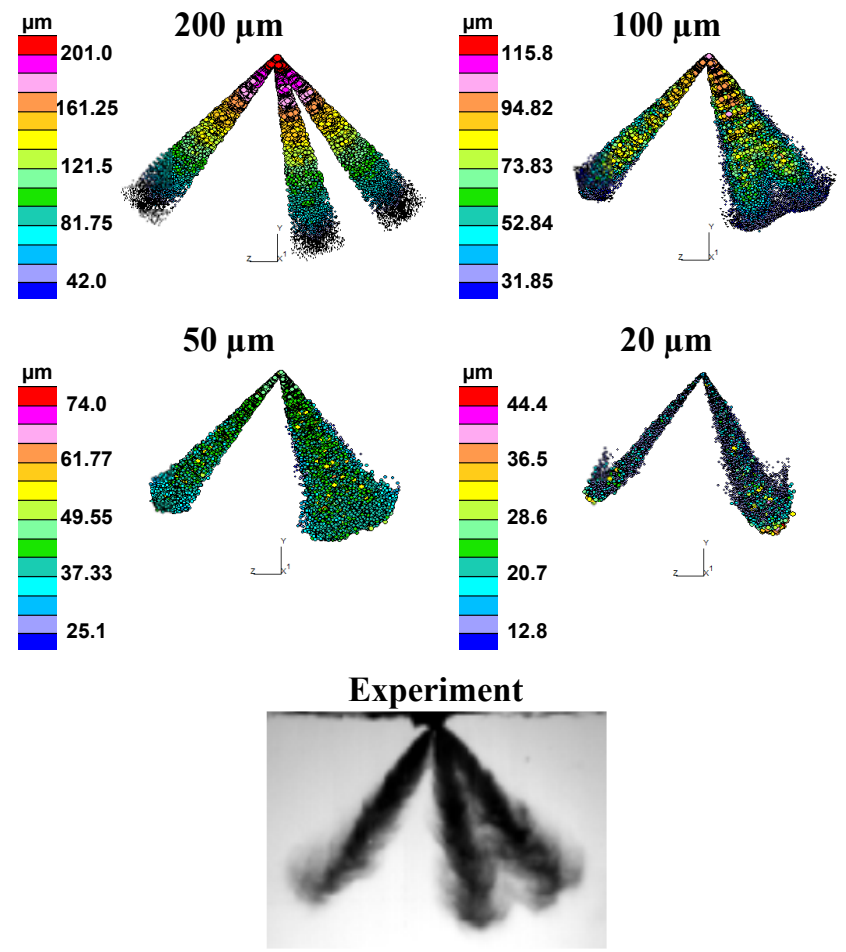

Figure 18. Spray formation of iso-Octane with varying initial droplet diameter at $P_{\infty}=0.5$ bar and $T_{f}=120{ }^{\circ} \mathrm{C}$.

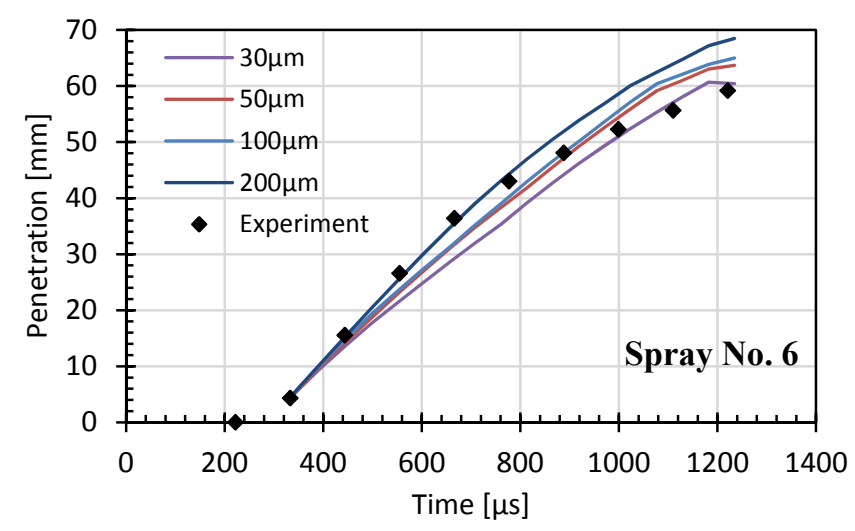

Figure 19. Penetration of iso-Octane with varying initial droplet diameter at $P_{\infty}=0.5$ bar and $T_{f}=120^{\circ} \mathrm{C}$.

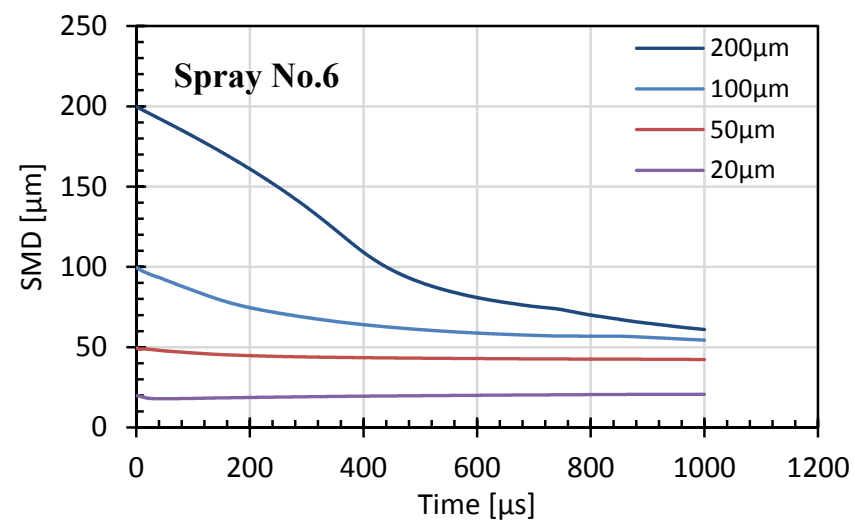

Figure 20. SMD of iso-Octane with varying initial droplet diameter at $P_{\infty}=0.5$ bar and $T_{f}=120{ }^{\circ} \mathrm{C}$.

Page 13 of 23

\section{Individual Plume Cone Angle}

Displayed in Figure 21 is the spray formation of superheated $n$-Pentane at $P_{\infty}=0.5$ bar and $T_{f}=90{ }^{\circ} \mathrm{C}$ using an initial droplet diameter of $D_{d}=20 \mu \mathrm{m}$. It is clear that the spray formation calculated contained the collapsing mechanism, producing a spray with broadly similar characteristics to those of the experiment. Plumes 2 and 3, as well as 4 and 5, fully collapsed and the cone angle of plumes 1 and 6 diminished to an angle of $\theta=13^{\circ}$ (an angle of $15^{\circ}$ is illustrated). A curvature of the plumes is also apparent.
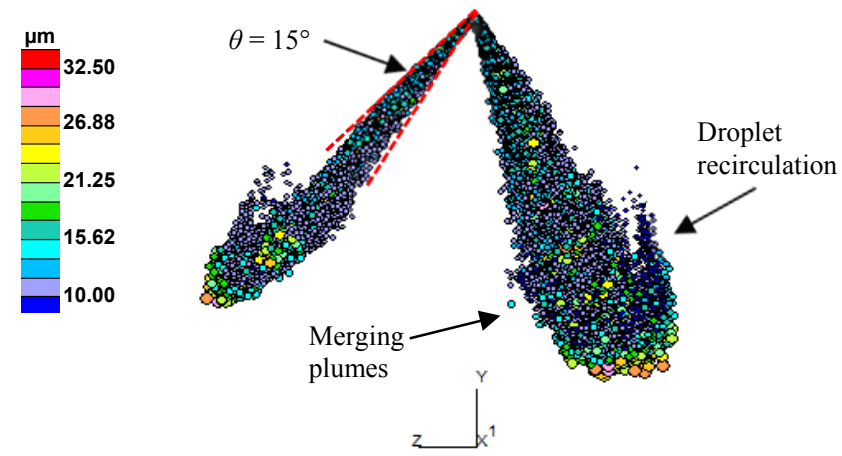

Figure 21. Spray formation of n-Pentane at $P_{\infty}=0.5$ bar and $T_{f}=90^{\circ} \mathrm{C}$ using an initial droplet diameter of $20 \mu \mathrm{m}$.

An additional factor affecting the spray formation was the individual plume cone angle. It is evident from literature and experimental data that two-phase flows rapidly expand upon the nozzle exit, caused by a sudden reduction in pressure and simultaneous bubble growth/bursting. The current computational framework uses a constant user specified cone angle, which will not model the increasing angle with increasing superheat. Here, an initial study was carried out to investigate the effect of individual cone angle, with the scope to implement a model for automated calculation of this cone angle over a range of conditions based on empirical data as future work. The spray experiments with this injector have illustrated the mechanism of gradual widening of the plumes at the nozzle exit at superheated conditions [10], [25]. Additionally, other studies with single-hole injection nozzles have found that increasing the superheat and flashing of a spray caused a significant widening of the cone angle at the nozzle exit, in some cases it reached angles in the order of $100^{\circ}[43]$.

Figure 22 shows the spray formation of $n$-Pentane at $P_{\infty}=0.5$ bar and $T_{f}=90^{\circ} \mathrm{C}$ with an increased cone angle of $\theta=30^{\circ}$ and $\theta=45^{\circ}$ as opposed to the original angle of $\theta=15^{\circ}$. It was found that increasing the cone angle to $\theta=30^{\circ}$ produced a larger tip spreading of the plumes, and qualitatively a closer match to the collapsed experimental spray at the same conditions. The amount of collapse remained similar to that of $\theta=15^{\circ}$. However, a larger number of droplets surrounding the bulk liquid were observed. This effect was also witnessed when further increasing the cone angle to $\theta=45^{\circ}$, where a larger number of droplets resided in the area surrounding the bulk spray. An interesting comparison of 'footprint' shape was 
made between the numerically modelled spray and experiment. The general trend of plumes 1 and 6 was captured, where the two plumes are drawn together. The influence of flash-boiling is also somewhat captured in plumes 2, 3, 4 and 5, whereby plumes 2 and 3, and 4 and 5 merge into two distinct plumes. These two merged plumes begin to collapse together, creating a large spread of droplets over a wide angle which was observable in the high-speed image of the severely flash-boiling gasoline spray.
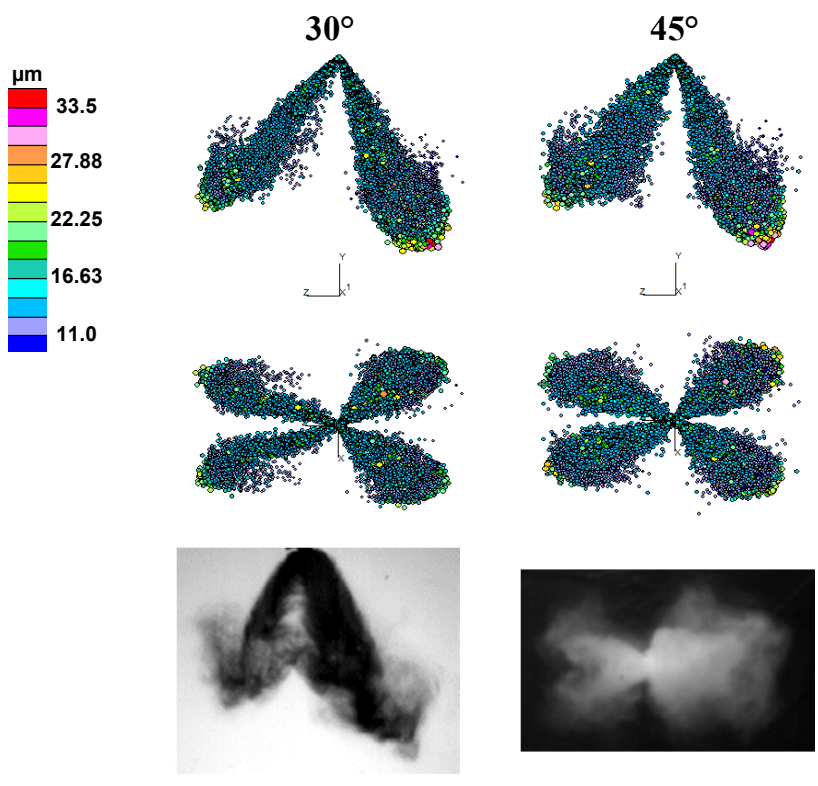

Figure 22. Spray formation of n-Pentane at $P_{\infty}=0.5$ bar and $T_{f}=90^{\circ} \mathrm{C}$ using an individual cone angle of $30^{\circ}$ and $45^{\circ}$ with initial droplet diameter of $20 \mu \mathrm{m}$.

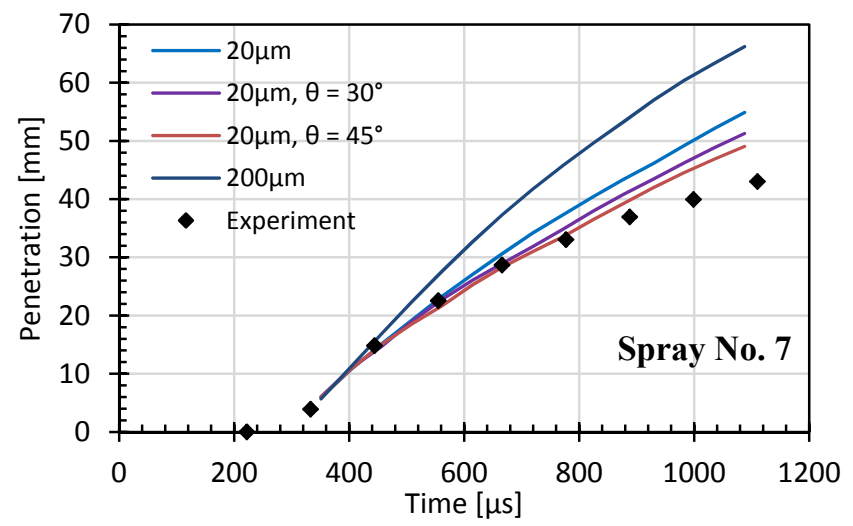

Figure 23. Penetration of n-Pentane with varying initial droplet diameter and plume cone angle at $P_{\infty}=0.5$ bar $T_{f}=$ $90{ }^{\circ} \mathrm{C}$.

The spray penetrations are plotted against experimental data in Figure 23. The influence of individual plume cone angle is displayed for $n$-Pentane fuel. The prediction of spray collapse alongside droplet diameter caused a substantial reduction in penetration, coinciding with experimental data, which displayed a smaller penetration for a collapsed spray. A substantial reduction in penetration is seen for the change in initial droplet diameter from $D_{d}=200 \mu \mathrm{m}$ to $D_{d}=20 \mu \mathrm{m}$, producing a length of $46 \mathrm{~mm}$ and $38 \mathrm{~mm}$ at $800 \mu \mathrm{s}$ ASOI, respectively. The penetration is further reduced with an increase in individual cone angle from $\theta=15^{\circ}$ to $30^{\circ}$ and $45^{\circ}$.

The fact that the individual cone angle can have a substantial effect on plume penetration was further studied by simulating the most extreme flash-boiling condition whereby an injection temperature of $T_{f}=180{ }^{\circ} \mathrm{C}$ and an ambient pressure of $P_{\infty}=$ 0.3 bar were simulated. The individual cone angles were varied from $\theta=45^{\circ}$ to $\theta=60^{\circ}$. Droplet initial diameters of 20 $\mu \mathrm{m}$ were applied with both $n$-Pentane and iso-Octane fuels. The spray formation predicted is displayed in Figures 24 and 25 .
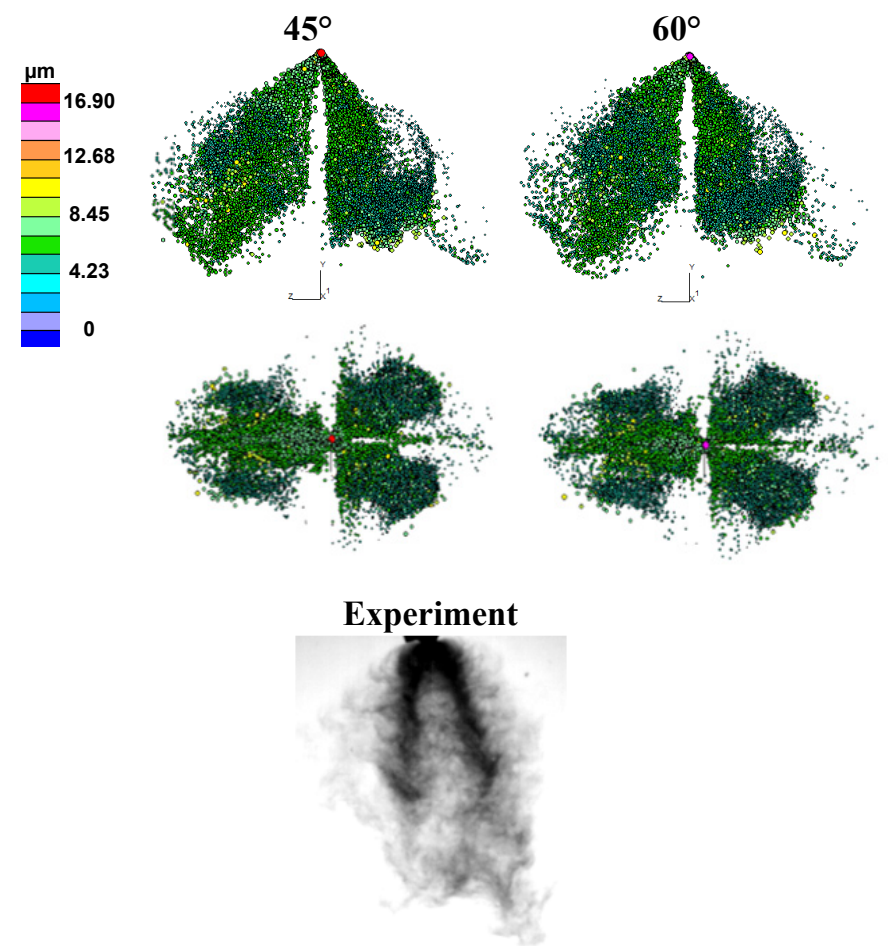

Figure 24. Spray formation of n-Pentane at $T_{f}=180^{\circ} \mathrm{C}$ and $P_{\infty}=0.3$ bar with individual plume cone angle of $45^{\circ}, 60^{\circ}$.

In the case of $n$-Pentane, a significant amount of droplet recirculation is captured, caused by the rapid evaporation and subsequent minute droplets residing at the leading edge of the plume, which decelerate quickly and are overtaken by larger droplets. The increasing cone angle results in a large spread of droplets, and the inner most droplets are seen to almost merge to produce a single collapsed spray with respect to the side view. The footprint view is also displayed in Figure 24 and shows plumes 1 and 6 fully merging at both $\theta=45^{\circ}$ and $60^{\circ}$, which is also the case for plumes 2, 3, 4 and 5. The same effect is found in flash-boiling iso-Octane fuel sprays in Figure 25, where an increased cone angle promotes dropletdroplet interaction and encourages plume merging and collapse. The resultant severe flashing spray formation found in the case of iso-Octane displayed less collapse, when compared to $n$-Pentane. This is expected due to the superheat degree being considerably smaller.

Page 14 of 23 

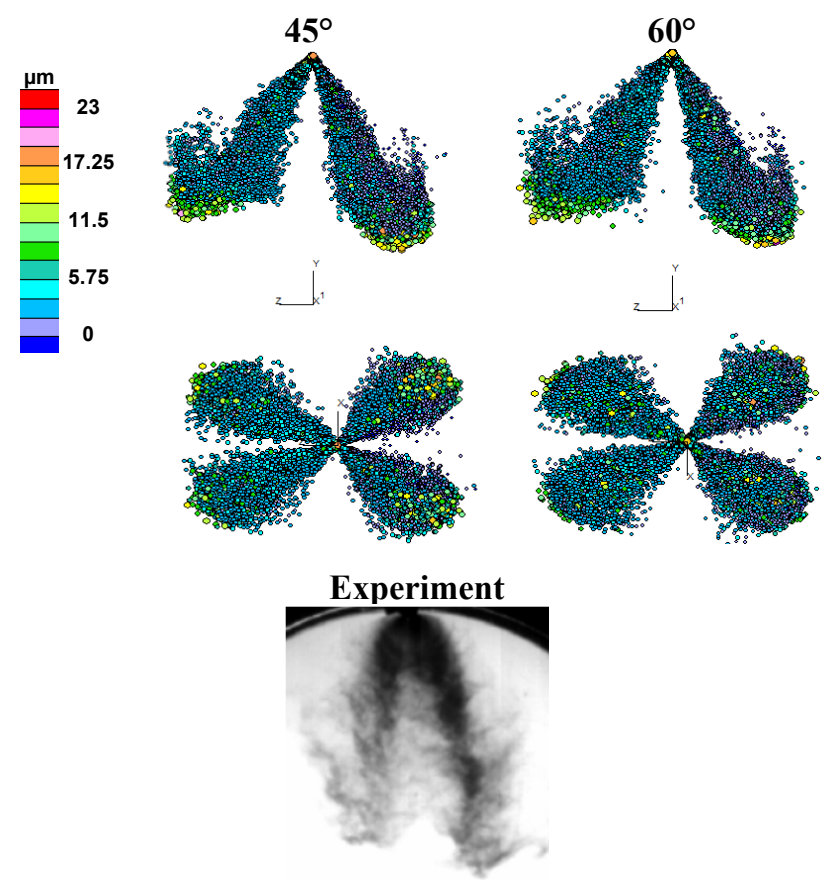

Figure 25. Spray formation of iso-Octane at $T_{f}=180^{\circ} \mathrm{C}$ and $P_{\infty}=0.3$ bar with individual plume cone angle of $45^{\circ}, 60^{\circ}$.

\section{$\underline{\text { Heat Transfer Coefficient }}$}

The final parameter investigated is the heat transfer coefficient $\alpha$ in Equation (4). The original empirical relationships of Equation (5) were developed by the work of [15], [22]. An initial investigation was carried out here by changing the highest regime coefficient ' $x$ ', as displayed in Equation 16, from the default value of 0.39 to 1.50 and then 3.00. To keep this exercise simple, 13800 was kept fixed despite the change in ' $x$ ' and it was considered that $\alpha$ maintained units of $\mathrm{W} / \mathrm{m}^{2} \mathrm{~K}$.

$$
\alpha=13800 \Delta T^{x} \text { when } \Delta T \geq 25
$$

Three initial droplet diameters were modelled at each ' $x$ ' value, at a collapsing condition of $n$-Pentane, specifically $P_{\infty}=$ 0.5 bar and $T_{f}=90^{\circ} \mathrm{C}$. Displayed in Figures 26, 27 and 28 are spray characteristics including droplet diameter, spray shape and vapor mass fraction. It was clear that the increase in exponent $x$ significantly affected the evaporation rate at flash boiling conditions above the $25^{\circ} \mathrm{C}$ superheat threshold. Figure 26 displays the effect of increasing $x$ on a flash-boiling spray with initial droplet diameter droplets of $D_{d}=20 \mu \mathrm{m}$. It should be noted that $82 \%$ of droplets completely evaporated in the case of $x=3.00$. In terms of spray formation a more significant collapse was seen with an increase in evaporation, a result of smaller droplets caused by rapid evaporation upon exit of the nozzle in the extreme case of $x=3.00$. A smaller effect is seen when $x=1.5$, due to droplets remaining relatively large in comparison to $x=0.39$. The distribution of vapor in the quiescent chamber was seen to cover a substantially larger area caused by large evaporation rates close to the nozzle exit.

Page 15 of 23

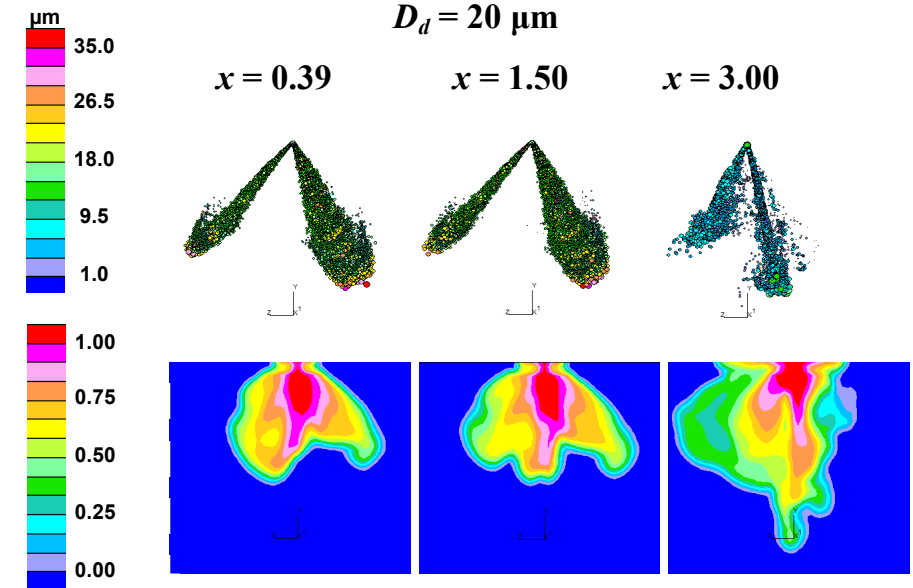

Figure 26. Effect of heat transfer exponent on spray of $n$ Pentane at $P_{\infty}=0.5 \mathrm{bar}, \mathrm{T}_{f}=90^{\circ} \mathrm{C}$, with initial droplet diameter $20 \mu \mathrm{m}$.

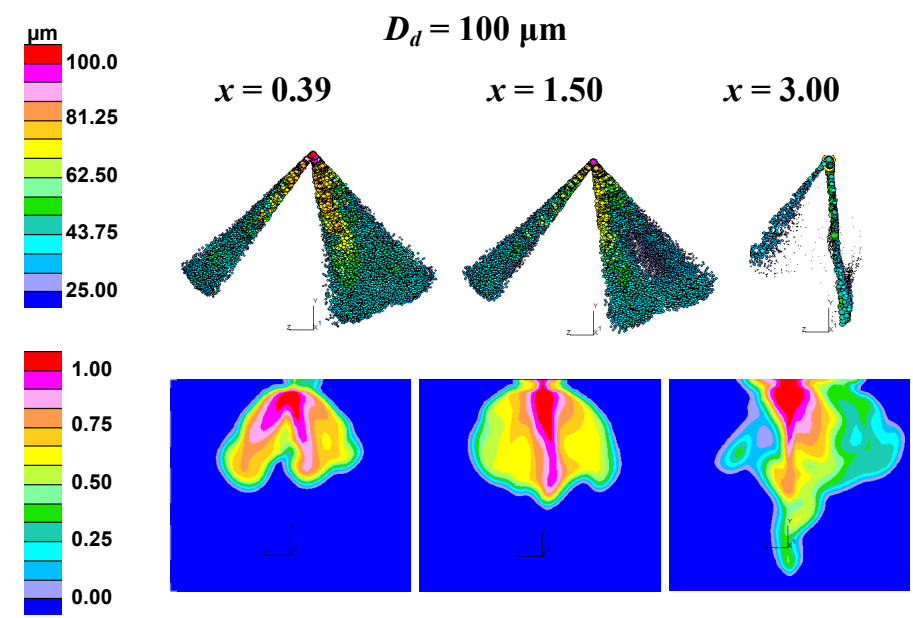

Figure 27. Effect of heat transfer exponent on spray of nPentane at $P_{\infty}=0.5 \mathrm{bar}, \mathrm{T}_{f}=90^{\circ} \mathrm{C}$, with initial droplet diameter $100 \mu \mathrm{m}$.

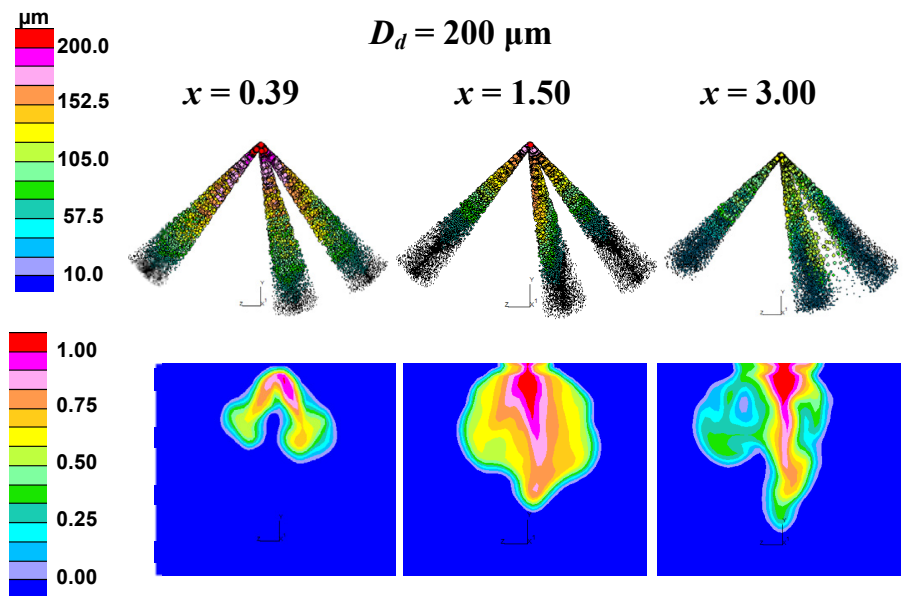

Figure 28. Effect of heat transfer exponent on spray of $n$ Pentane at $P_{\infty}=0.5 \mathrm{bar}, \mathrm{T}_{f}=90^{\circ} \mathrm{C}$, with initial droplet diameter $200 \mu \mathrm{m}$. 
A similar trend was seen in the case of $D_{d}=100 \mu \mathrm{m}$, displayed in Figure 27. Again the majority (86\%) of droplets completely evaporated in the case of $x=3.00$, leaving a small percentage of 'active' liquid droplets. It can be seen that the remaining droplets congregated to produce a very narrow plume. It was also apparent that the active droplets are positioned asymmetrically, suggesting the stochastic elements associated with the Lagrangian modelling approach have influenced the evaporation of individual plumes. The spray produced using $x=1.5$ is below the evaporation limit which causes total evaporation of the majority of droplets, hence the modelled spray is similar in shape to that of $x=0.39$.

To understand the effect of the heat transfer exponent $x$ on a spray which contains droplets large enough to endure the resultant rapid evaporation from $x=3.00$, one can study the spray with an initial droplet diameter of $D_{d}=200 \mu \mathrm{m}$, which is displayed in Figure 28. The onset of spray collapse, in the form of plume merging, was found to occur in this case with $x$ $=3.00$. Droplets rapidly reduced in size, reaching $100 \mu \mathrm{m}$ diameter almost immediately after leaving the nozzle exit. This significant reduction in droplet diameter, encourages droplet-droplet collisions and air entrainment from jet tip vorticities, subsequently resulting in the onset of plume merging. A significant increase in vapor mass fraction is again observed, whereby the vapor is induced into the central area of the injector, highlighting the flow produced by the collapsing mechanism. An interesting observation from this investigation was the effect of droplet diameter on vapor mass fraction. It was evident that smaller droplets increase the amount of vapor produced, caused by the increased surface area and surface evaporation caused by heat transfer from internally superheated liquid droplets.

A quantitative comparison between $x=0.39,1.5$ and 3.00 at various droplet diameters was also made via plume penetration and SMD, as displayed in Figures 29 and 30, respectively. In all cases the penetration is seen to reduce with increased evaporation. In the extreme case of $20 \mu \mathrm{m}$ and $x=$ 3.00 where the plumes are seen to come together, a significant reduction in penetration was predicted, producing a spray penetration very close to that of the experimental penetration curve for the collapsing $n$-Pentane spray.

The SMD, displayed in Figure 30, clearly shows the reduction in droplet sauter mean diameter with increased evaporation at superheat degrees of $\Delta T>25{ }^{\circ} \mathrm{C}$. At $400 \mu$ s ASOI the reduction in SMD at $x=3.00$ was found to be $28.2 \%, 63.1 \%$ and $41.6 \%$ for $D_{d}=200 \mu \mathrm{m}, 100 \mu \mathrm{m}$ and $20 \mu \mathrm{m}$, respectively. The reason for SMD values at $x=3.00$ not being present until $50 \mu \mathrm{s}$ ASOI is due to the total evaporation of droplets up until this point, preventing an SMD value from being taken. Droplets injected prior to $50 \mu$ s undergo almost instantaneous evaporation within single time steps due to the increased heat transfer coefficient. The rapid evaporation of these initial droplets produces a high concentration of vapor, eventually saturating the group of cells surrounding the nozzle exit, allowing a number of droplets after $50 \mu$ s to survive due to the Page 16 of 23 evaporation rate diminishing with an increase in vapor concentration.

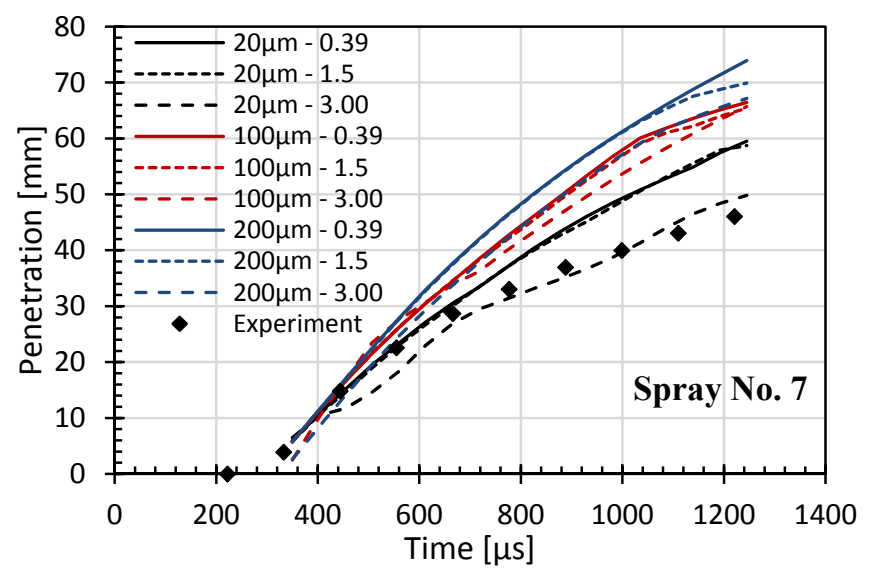

Figure 29. Effect of heat transfer coefficient on spray penetration of $n$-Pentane at $P_{\infty}=0.5$ bar and $T_{f}=90^{\circ} \mathrm{C}$ with numerous initial droplet diameters.

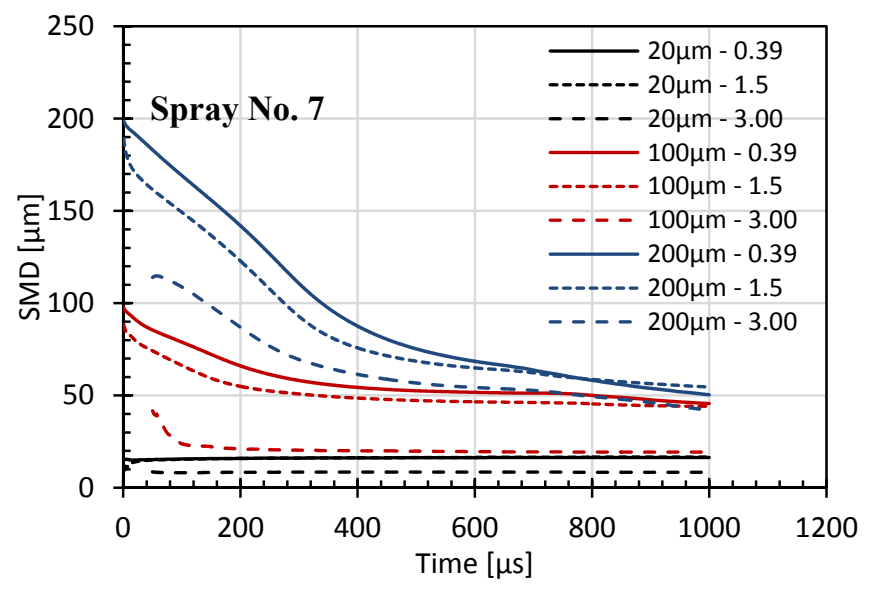

Figure 30. Effect of heat transfer coefficient on predicted $S M D$ of $n$-Pentane at $P_{\infty}=0.5$ bar and $T_{f}=90{ }^{\circ} \mathrm{C}$ with numerous initial droplet diameters.

To summarise the current work, spray collapse was somewhat predicted for both fuels at numerous conditions. It is concluded that the initial droplet diameter alongside the evaporation model and droplet collision model can be used to predict some form of spray collapse. Large initial droplets can be applied to achieve a non-collapsing spray and small initial droplets can be applied to model a flash-boiling collapsing spray, which corresponds to bubble nucleation physics and droplet formation inside of the nozzle. Currently, a number of limitations exist regarding modelling flash-boiling fuel spray physics; these include thermal break-up caused by bubble nucleation and growth inside superheated droplets, an accurate initial droplet diameter relationship based on fuel properties and injection conditions and an accurate individual spray plume cone angle also dependent on fuel properties and injection conditions. A carefully considered combination of all 
of the above mentioned parameters is needed for a versatile flash-boiling numerical model. Work in progress by the current authors is based on the development and implementation of a relationship which will automatically calculate the appropriate initial droplet diameter and spray cone angle based upon nozzle conditions and fuel properties. This will automatically determine the degree of spray collapse alongside the flash-boiling evaporation methodology of the current investigation.

\section{CONCLUSIONS}

The current numerical study used a Lagrangian Particle Tracking two-phase methodology in order to reproduce subcooled and superheated sprays for advanced direct injection internal combustion engines. A flash-boiling evaporation model was implemented into STAR-CD and validated qualitatively and quantitatively against experimental data with fuel temperatures as high as $180{ }^{\circ} \mathbf{C}$ and gas pressures as low as 0.3 bar. Moreover, sensitivity studies were conducted to examine the effect of key simulation parameters on the characteristics of flashing iso-Octane and $n$-Pentane sprays. The main conclusions of the present study can be summarized as follows:

- By adjusting the parameters of the droplet break-up model, it was possible to improve the predicted spray formation in terms of spray bulk shape, penetration length and SMD with respect to experimental data, but overall even the default constants offered predictions well within $10 \%$ of experiments at non-collapsing subcooled spray conditions. Nevertheless, application to superheated flashing sprays would require tuning beyond the model's designed compatibility with standard mechanisms of primary and secondary spray break-up.

- The implemented evaporation model was able to predict increased vapor concentration and enlarged vapor areas caused by the additional energy of superheat over a range of fuel temperatures and gas pressures.

- The droplet collision model was found to be an influential factor regarding the ability of the developed numerical framework to predict flash-boiling spray collapse via plume merging phenomena. The effect was strongest by a reduction in droplet sizes.

- Varying the initial droplet diameter and individual cone angle resulted in a more realistic representation of a flashing multi-hole fuel spray, in terms of both the overall spray structure and its volumetric growth. The predicted penetration was $20-30 \%$ lower when the initial droplet diameter was reduced from $200 \mu \mathrm{m}$ to $20 \mu \mathrm{m}$ at superheated conditions.

- The heat transfer coefficient in the superheated evaporation term was found to be an area with strong potential for model optimization. A significant promotion of evaporation was achieved, subsequently enhancing the mechanism of spray collapse. In the case of initial droplet diameter of $20 \mu \mathrm{m}$, an increase in the value of the superheat exponent by an order of magnitude led to a Page 17 of 23 predicted plume penetration that matched the experimental data closely during most of the injection event with a typical agreement of 5-8\%.

With the acquired knowledge, improvements to the current methodology for modelling flash-boiling sprays are currently being carried out by:

- Implementing a thermophysical model to automatically predict the initial droplet diameter and individual spray plume cone angle, associated with correct representation of in-cylinder physics at conditions typical of low-load engine operation.

- Optimize the developed framework using a droplet breakup model which incorporates the effects of thermal breakup in the form of bubble bursting and collapse. The proposed methodology may apply additional break-up regimes based on a combination of non-dimensional numbers, including the Jakob number.

\section{REFERENCES}

[1] S. Nagumo and S. Hara, "Study of fuel economy improvement through control of intake valve closing timing: cause of combustion deterioration and improvement," JSAE Rev., vol. 16, pp. 13-19, 1995. doi:10.1016/0389-4304(94)00048-X

[2] N. Ashgriz, Handbook of atomization and sprays theory and applications. London: Springer, 2011.

[3] C. Song, "An overview of new approaches to deep desulfurization for ultra-clean gasoline, diesel fuel and jet fuel," Catal. Today, vol. 86, pp. 211-263, 2003. doi:10.1016/S0920-5861(03)00412-7

[4] P. G. Aleiferis, J. Serras-Pereira, Z. van Romunde, J. Caine, and M. Wirth, "Mechanisms of spray formation and combustion from a multi-hole injector with E85 and gasoline," Combust. Flame, vol. 157, no. 4, pp. 735-756, Apr. 2010. doi:10.1016/j.combustflame.2009.12.019

[5] J. Serras-Pereira, P. G. Aleiferis, and D. Richardson, "Imaging and Heat Flux Measurements of Wall Impinging Sprays of Hydrocarbons and Alcohols in a Direct-Injection Spark-Ignition Engine," Fuel, vol. 91, no. 1, pp. 264-297, 2012. doi:10.1016/j.fuel.2011.07.03

[6] J. Serras-Pereira, P. G. Aleiferis, H. L. Walmsley, T. J. Davies, and R. F. Cracknell, "Heat Flux Characteristics of Spray Wall Impingement with Ethanol, Butanol, Iso-Octane, Gasoline and E10 Fuels," Int. J. Heat Fluid Flow, vol. 44, pp. 662-683, 2013. doi:10.1016/j.ijheatfluidflow.2013.09.010 
P. G. Aleiferis, M. Behringer, D. OudeNijeweme, and P. Freeland, "Spray Imaging and Droplet Sizing of Spark-Eroded and Laser-Drilled Injectors with Gasoline-Butanol and Gasoline-Ethanol Blends," in Internaltional Conference on Fuel Systems for IC Engines IMechE, 2015.

[8] P. G. Aleiferis, J. Serras-Pereira, A. Augoye, T. J. Davies, R. F. Cracknell, and D. Richardson, "Effect of Fuel Temperature on In-Nozzle Cavitation and Spray Formation of Liquid Hydrocarbons and Alcohols from a Real-Size Optical Injector for Direct-Injection Spark-Ignition Engines," Int. J. Heat Mass Transf., vol. 53, no. 21-22, pp. 4588-4606, 2010. doi:10.1016/j.ijheatmasstransfer.2010.06.033

[9] J. Serras, P. G. Aleiferis, and D. Richardson, “An experimental database on the effects of single and split injection strategies on spray formation and spark discharge in an optical DISI engine fuelled with gasoline, iso-octane and alcohols," Int. J. Engine, pp. 1-70. doi: $10.1177 / 1468087414554936$.

[10] P. G. Aleiferis and Z. R. van Romunde, "An analysis of spray development with iso-octane, n-pentane, gasoline, ethanol and n-butanol from a multi-hole injector under hot fuel conditions," Fuel, vol. 105, pp. 143-168, Mar. 2013. doi:10.1016/j.fuel.2012.07.04

[11] E. Sher, T. Bar-Kohany, and A. Rashkovan, "Flashboiling atomization," Prog. Energy Combust. Sci., vol. 34, no. 4, pp. 417-439, Aug. 2008. doi:10.1016/j.pecs.2007.05.001

[12] E. Sher and C. Elata, "Spray Formation from Pressure Cans by Flashing," Ind. Eng. Chem. Process Des. Dev., vol. 16, no. 2, pp. 237-242, Apr. 1977. doi: $10.1021 / \mathrm{i} 260062 \mathrm{a} 014$

[13] Y. Kitamura, H. Morimitsu, and T. Takahashi, "Critical superheat for flashing of superheated liquid jets," Ind. Eng. Chem. Fundam., vol. 25, no. 2, pp. 206-211, 1986. doi: 10.1021/i100022a005

[14] M. Levy, Y. Levy, and E. Sher, "Spray structure as generated under homogeneous flash boiling nucleation regime," Appl. Therm. Eng., vol. 73, no. 1, pp. 414421, Dec. 2014.

doi:10.1016/j.applthermaleng.2014.08.008

[15] M. Adachi, D. Tanaka, Y. Hojyo, A. Marwan, J. Senda, and H. Fujimoto, "Measurment of Fuel Vapor Concentration in Flash Boiling Spray by Infrared Extinction/Scattering Technique," JSAE Review, vol. 17, pp. 231-237, 1996. doi:10.1016/0389$\underline{4304(96) 00025-2}$

Page 18 of 23
[16] J. Senda, Y. Hojyo, and H. Fujimoto, "Modelling of Atomization Process in Flash Boiling Spray," SAE Tech. Pap. 941925, no. 412, 1994. doi: $\underline{10.4271 / 941925}$

[17] Y. Ra and R. D. Reitz, "The application of a multicomponent droplet vaporization model to gasoline direct injection engines," Int. J. Engine Res., vol. 4, no. 3, pp. 193-218, Jan. 2003. doi: $10.1243 / 146808703322223388$

[18] G. Polanco, A. E. Holdø, and G. Munday, "General review of flashing jet studies.," J. Hazard. Mater., vol. 173, no. 1-3, pp. 2-18, Jan. 2010. doi:10.1016/j.jhazmat.2009.08.138

[19] R. I. Issa, "Solution of the implicitly discretised fluid flow equations by operator-splitting," J. Comput. Phys., vol. 62, pp. 40-65, 1986. doi:10.1016/00219991(86)90099-9

[20] V. Yakhot, S. A. Orszag, S. Thangam, T. B. Gatski, and C. G. Speziale, "Development of turbulence models for shear flows by a double expansion technique," Physics of Fluids, vol 1510. 1992.

[21] J. Malcolm, M. Behringer, P. Aleiferis, and J. Mitcalf, "Characterisation of flow structures in a directinjection spray-ignition engine using PIV, LDV and CFD," SAE Tech. Pap. 2011. doi:10.4271/2011-01$\underline{1290}$

[22] A. D. Gosman and E. Loannides, "Aspects of Computer Simulation of Liquid-Fueled Combustors," J. Energy, vol. 7, no. 6, pp. 482-490, 1983. doi: $10.2514 / 3.62687$

[23] C. L. Yaws, Yaws' hanbook of thermodynamic and physical properties of chemical compounds: physical, thermodynamic and transport properties for 5,000 organic chemical compounds. 2003.

[24] R. D. Reitz, "A Photographic Study of Flash-Boiling Atomization," Aerosol Sci. Technol., vol. 12, no. 3, pp. 561-569, Jun. 2007. doi: $10.1080 / 02786829008959370$

[25] J. Serras-Pereira, Z. van Romunde, P. G. Aleiferis, D. Richardson, S. Wallace, and R. F. Cracknell, "Cavitation, primary break-up and flash boiling of gasoline, iso-octane and n-pentane with a real-size optical direct-injection nozzle," Fuel, vol. 89, no. 9, pp. 2592-2607, Sep. 2010.

[26] A. J. Butcher, P. G. Aleiferis, and D. Richardson, "Development of a Real-Size Optical Injector Nozzle 
for Studies of Cavitation, Spray Formation and Flash Boiling at Conditions Relevant to Direct-Injection Spark-Ignition Engines," Int. J. Engine Res., vol. 14, pp. 557-577, 2013. doi:10.1177/1468087413497004

[27] R. Bird, W. Stewart, and E. Lightfoot, Transport phenomena. 1966.

[28] D. B. Spalding, "The combustion of liquid fuels," Symp. Combust., vol. 4, pp. 847-864, 1953.

[29] M. Adachi, V. McDonell, and D. Tanaka, "Characterization of fuel vapor concentration inside a flash boiling spray," SAE Int., no. 412, 1997. doi: $10.4271 / 970871$

[30] E. Wakil, M, M, A. Uyehara, O, and S. Myers, P, "A theoretical investigation of the heating-up period of injected fuel droplets vaporizing in air," Natl. Advis. Com. Aeronaut., 1954.

[31] R. Reitz and R. Diwakar, "Effect of drop breakup on fuel sprays," SAE International. 1986. doi: $\underline{10.4271 / 860469}$

[32] P. J. O'Rouke and A. A. Amsden, "The tab method for numerical calculation of spray droplet breakup," $S A E$ Pap. 872089, 1987. doi: $10.4271 / 872089$

[33] D. P. Schmidt and C. J. Rutland, “A New Droplet Collision Algorithm," J. Comput. Phys., vol. 164, no. 1, pp. 62-80, Oct. 2000. doi:10.1006/jcph.2000.6568

[34] N. Nordin, "Complex Chemisty Modeling of Diesel Spray Combustion." Doctroral Thesis, Chalmers University of Technology, 2001.

[35] P. G. Aleiferis, M. Ashrafi-Nik, N. Ladommatos, G. Dober, and K. K, "A study of droplet collision modelling for spray formation and mixing with a tworow group-hole injection nozzle for diesel engines," At. Sprays. doi:10.1615/AtomizSpr.2014011025

[36] Z. Van Romunde, P. G. Aleiferis, R. Cracknell, and H. Walmsley, "Effect of fuel properties on spray development from a multi-hole DISI engine injector," SAE Int., 2007. doi:10.4271/2007-01-4032

[37] Z. Van Romunde and P. G. Aleiferis, "Effect of operating conditions and fuel volatility on development and variability of sprays from gasoline direct-injection multihole injectors," At. Sprays, vol. 19, pp. 207-234, 2009.

doi:10.1615/AtomizSpr.v19.i3.10
[38] M. Razzaghi, "Droplet size estimation of two-phase flashing jets," Nucl. Eng. Des., vol. 114, pp. 115-124, 1989. doi:10.1016/0029-5493(89)90130-1

[39] T. D. Fansler, M. C. Drake, B. Gajdeczko, I. Düwel, W. Koban, F. P. Zimmermann, and C. Schulz, "Quantitative liquid and vapor distribution measurements in evaporating fuel sprays using laserinduced exciplex fluorescence," Meas. Sci. Technol., vol. 20, p. 125401, 2009. doi:10.1088/0957$\underline{0233 / 20 / 12 / 125401}$

[40] A. Hamzehloo and P. G. Aleiferis, "Large eddy simulation of highly turbulent under-expanded hydrogen and methane jets for gaseous-fuelled internal combustion engines," Int. J. Hydrogen Energy, vol. 39, no. 36, pp. 21275-21296, 2014. doi:10.1016/j.ijhydene.2014.10.016

[41] M. Zhang, M. Xu, Y. Zhang, G. Zhang, and D. J. Cleary, "Flow-Field Investigation of Multihole Superheated Sprays Using High-Speed Piv. Part Ii. Axial Direction," At. Sprays, vol. 23, no. 2, pp. 119 140, 2013. doi:10.1615/AtomizSpr.2013007454

[42] M. Behringer, P. Aleiferis, D. OudeNijeweme, and P. Freeland, "Spray Formation from Spark-Eroded and Laser-Drilled Injectors for DISI Engines with Gasoline and Alcohol Fuels," SAE Int. J. Fuels Lubr. vol. 7, pp. 803-822, 2014, doi:10.4271/2014-01-2745.

[43] B. Park and S. Lee, "An experimental investigation of the flash atomization mechanism," At. Sprays, vol. 4, pp. 159-179, 1994. doi:10.1615/AtomizSpr.v4.i2.30.

\section{CONTACT INFORMATION}

Dr. Pavlos Aleiferis

University College London

Department of Mechanical Engineering

Torrington Place, London WC1E 7JE, UK

E-mail: p.aleiferis@ucl.ac.uk

\section{ACKNOWLEDGEMENTS}

Jaguar Land Rover are gratefully acknowledged for the financial and technical support of Christopher James Price via an ESPRC CASE award. EPSRC are also acknowledged for their financial support of Arash Hamzehloo on research grant number EP/M009424/1. The authors also acknowledge the use of the UCL Legion High Performance Computing Facility (Legion@UCL), and associated support services, in the completion of this work. The authors would also like to thank all members of the UCL Internal Combustion Engines Group for their assistance and many valuable discussions. 


\section{DEFINITIONS/ABBREVIATIONS}

$A \quad$ Area

$P_{\infty} \quad$ Ambient pressure

$T_{\infty} \quad$ Ambient Temperature

$P_{v} \quad$ Vapor pressure

$P_{s} \quad$ Saturation pressure

$P_{s g} \quad$ Saturation pressure at surrounding gas

Sh Sherwood number

$D \quad$ Binary diffusivity coefficient in air

$\alpha \quad$ Heat transfer coefficient (Adachi model)

$T_{f} \quad$ Film temperature

$R_{f} \quad$ Specific gas constant of film

$D_{d} \quad$ Instantaneous droplet diameter

$\Delta T \quad$ Superheat degree

$H_{V} \quad$ Latent heat of vaporization

$Y \quad$ Fuel vapor mass fraction in cell

$Y_{s} \quad$ Fuel vapor mass fraction at droplet surface

$m_{a} \quad$ Molecular weight of air

$m_{v} \quad$ Molecular weight of fuel vapor

$M_{t} \quad$ Total evaporated mass

$M_{s c} \quad$ Subcooled evaporated mass

$M_{s h} \quad$ Superheated evaporated mass

$T_{b} \quad$ Boiling temperature of fuel

$T_{d} \quad$ Instantaneous droplet temperature

$h \quad$ Heat transfer coefficient

$D_{d, \text { stable }} \quad$ Stable droplet diameter

$\tau_{b} \quad$ Bag break-up timescale

$\tau_{s} \quad$ Stripping break-up timescale

We Weber number

$U_{l, 2} \quad$ Relative droplet velocity

$u_{1}$ and $u_{2} \quad$ Droplet velocity vector

$X_{1}$ and $X_{2} \quad$ Droplet position vector

$K$

Relative motion factor

Re Reynold's number

Sc Schmidt number

$\mathrm{Nu} \quad$ Nusselt number

$\mathrm{Pr} \quad$ Prandtl number

$u \quad$ Eulerian phase velocity at droplet position

$u_{d} \quad$ Droplet velocity

$\rho \quad$ Density

$\sigma \quad$ Surface tension

$C_{p} \quad$ Specific heat capacity at constant pressure

$v \quad$ Viscosity

$k \quad$ Thermal conductivity

$x \quad$ Heat transfer exponent 


\section{APPENDIX A}

\section{iso-Octane Fuel Property Polynomials}

$\rho=10^{3}\left(0.2456 \cdot 0.2737^{\left(1-\left(T_{d} / 543.96\right)^{0.2846}\right)}\right)\left[\mathrm{kg} / \mathrm{m}^{3}\right]$

$\sigma=10^{-3}\left(47.434\left(1-\left(\frac{T_{d}}{543.96}\right)\right)^{1.1975}\right)[\mathrm{N} / \mathrm{m}]$

$H_{V}=\frac{10^{3}}{0.114}\left(42.901\left(1-\left(\frac{T_{d}}{543.96}\right)\right)^{0.281}\right)[\mathrm{J} / \mathrm{kg}]$

$C_{p}=\frac{122.772+\left(0.79485 T_{d}\right)-\left(2.4977 \cdot 10^{-3} T_{d}{ }^{2}\right)+\left(3.5652 \cdot 10^{-6} T_{d}{ }^{3}\right)}{0.114}[\mathrm{~J} / \mathrm{kg} \cdot \mathrm{K}]$

$\nu=10^{-3}\left(10^{-15.042+\left(\frac{2002.1}{T_{d}}\right)+\left(0.0371 T_{d}\right)-\left(3.4486 \cdot 10^{-5} T_{d}{ }^{2}\right)}\right)[\mathrm{kg} / \mathrm{m} \cdot \mathrm{s}]$

$k=0.1338-\left(4.6738 \cdot 10^{-5} T_{d}\right)-\left(2.1747 \cdot 10^{-7} T_{d}^{2}\right)[\mathrm{W} / \mathrm{m} \cdot \mathrm{K}]$

$\left.P_{s}=33.3224\left(10^{\left(50.342-\left(\frac{3278.9}{T_{d}}\right)-\left(16.111 \log _{10} T_{d}\right)+\left(0.007426 T_{d}\right)-\left(9.1804 \cdot 10^{-14} T_{d}^{2}\right)\right.}\right)\right)[\mathrm{Pa}]$

$D_{i}=\frac{-0.03648+\left(2.0520 \cdot 10^{-4} T_{f}\right)+\left(4.3354 \cdot 10^{-7} T_{f}{ }^{2}\right)}{10000}\left[\mathrm{~m}^{2} / \mathrm{s}\right]$

\section{n-Pentane Fuel Property Polynomials}

$\rho=10^{3}\left(0.2314 \cdot 0.2692^{-\left(1-\left(T_{d} / 469.65\right)^{0.2822}\right)}\right)\left[\mathrm{kg} / \mathrm{m}^{3}\right]$

$\sigma=10^{-3}\left(52.09\left(1-\left(\frac{T_{d}}{469.65}\right)\right)^{1.2054}\right)[\mathrm{N} / \mathrm{m}]$

$H_{V}=\frac{10^{3}}{0.07215}\left(39.854\left(1-\left(\frac{T_{d}}{469.65}\right)\right)^{0.398}\right)[\mathrm{J} / \mathrm{kg}]$ 
$C_{p}=\frac{80.641+\left(0.62195 T_{d}\right)-\left(2.2682 \cdot 10^{-3} T_{d}^{2}\right)+\left(3.7423 \cdot 10^{-6} T_{d}^{3}\right)}{0.077215}[\mathrm{~J} / \mathrm{kg} \cdot \mathrm{K}]$

$v=10^{-3}\left(10^{-7.1711+\left(\frac{747.36}{T_{d}}\right)+\left(0.0217 \times T_{d}\right)-\left(2.717 \times 10^{-5} \times T_{d}^{2}\right)}\right)[\mathrm{kg} / \mathrm{m} \cdot \mathrm{s}]$

$k=0.1877-\left(3.7842 \cdot 10^{-6} T_{d}\right)-\left(4.3481 \cdot 10^{-7} T_{d}^{2}\right)[\mathrm{W} / \mathrm{m} \cdot \mathrm{K}]$

$P_{s}=133.3224\left(10^{\left.33.324-\left(\frac{2422.7}{T_{d}}\right)-\left(9.2354 \log _{10} T_{d}\right)\right)+\left(9.0199 \cdot 10^{-11} T_{d}\right)-\left(4.105 \cdot 10^{-6} T_{d}^{2}\right)}\right)$

$D_{i}=\frac{-0.04629+\left(2.727 \cdot 10^{-4} T_{f}\right)+\left(5.5307 \cdot 10^{-7} T_{f}^{2}\right)}{10000}\left[\mathrm{~m}^{2} / \mathrm{s}\right]$

\section{Dimensionless Quantities}

$S h=2.0+0.6 R e^{0.5} S c^{0.333}$

$S c=\frac{v}{\rho D}$

$R e=\frac{\rho\left(u-u_{d}\right) d_{d}}{v}$

$N u=2.0+0.6 \operatorname{Re}^{0.5} \operatorname{Pr}^{0.333}$

$\operatorname{Pr}=\frac{C_{p} \mu}{k}$

$W e=\frac{\rho\left|u-u_{d}\right|^{2} D_{d, \text { stable }}}{2 \sigma}$ 


\section{APPENDIX B}

\section{Orientations of the Multi-hole Injector Nozzles with Nominal Injection Plumes}
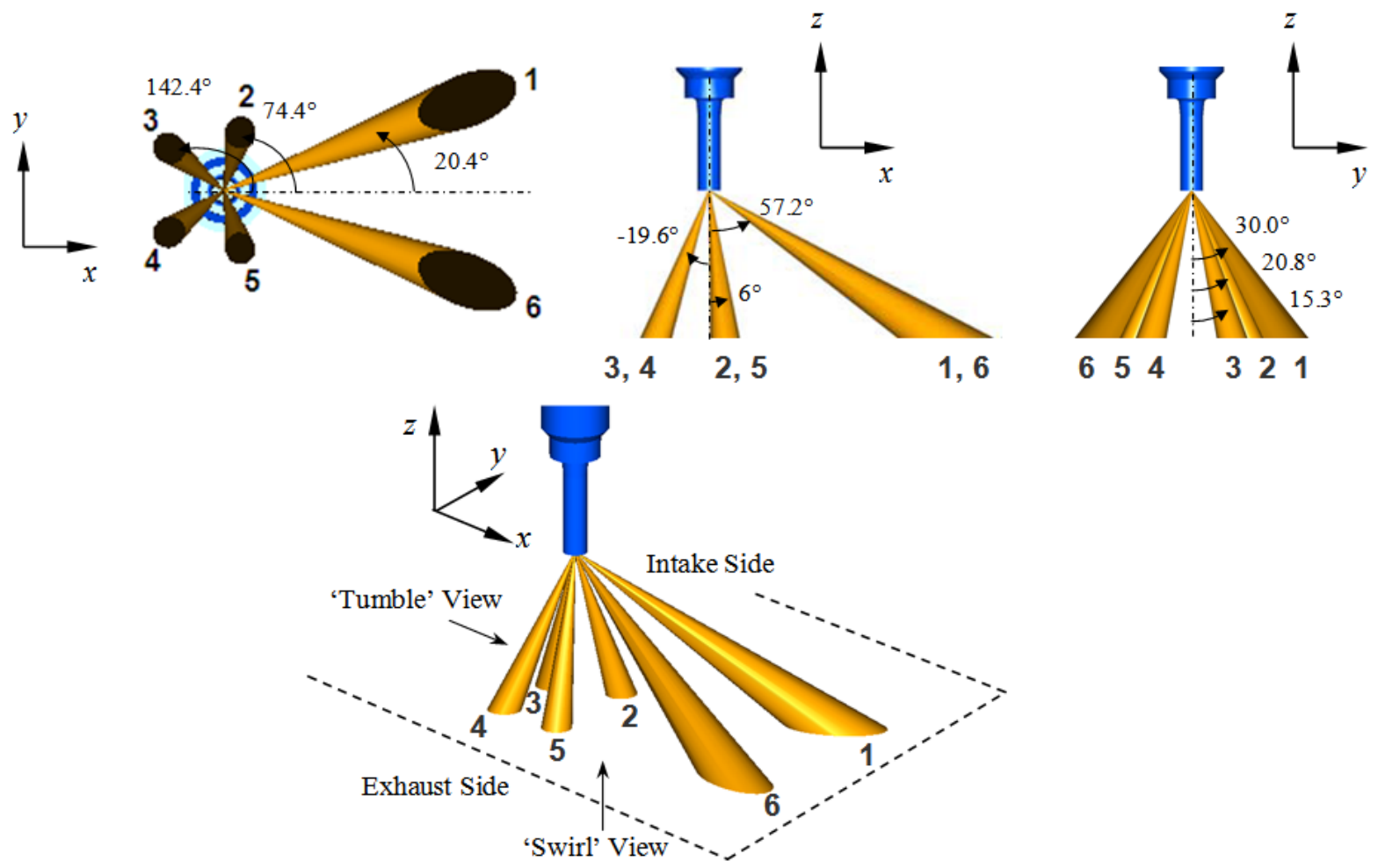

\begin{tabular}{|c|c|c|c|c|c|c|c|}
\hline & \multicolumn{3}{|c|}{ Nominal Values [mm] } & \multirow{2}{*}{$\begin{array}{c}\text { Offset } \\
\text { Angle }\end{array}$} & \multicolumn{2}{c|}{ Proj. Separation } & \multirow{2}{*}{$\begin{array}{c}\text { Proj. } \\
\text { Angle }\end{array}$} \\
\cline { 1 - 1 } Plume & $\mathbf{x}$ & $\mathbf{y}$ & $\mathbf{z}$ & & Sprays & Angle & Ang. \\
\hline $\mathbf{1}$ & 77.54 & 28.89 & 50.00 & 58.9 & $6-1$ & 40.9 & 20.4 \\
\hline $\mathbf{2}$ & 5.30 & 19.00 & 50.00 & 21.5 & $1-2$ & 54.0 & 74.4 \\
\hline $\mathbf{3}$ & -17.77 & 13.70 & 50.00 & 24.2 & $2-3$ & 68.0 & 142.4 \\
\hline $\mathbf{4}$ & -17.77 & -13.70 & 50.00 & 24.2 & $3-4$ & 75.3 & 217.6 \\
\hline $\mathbf{5}$ & 5.30 & -19.00 & 50.00 & 21.5 & $4-5$ & 68.0 & 285.6 \\
\hline $\mathbf{6}$ & 77.54 & -28.89 & 50.00 & 58.9 & $5-6$ & 54.0 & 339.6 \\
\hline
\end{tabular}

